\title{
AldeAs EN LOS BOSQUES DE PROSOPIS. ARQUITECTURA RESIDENCIAL Y CONGREGACIONAL EN EL PERÍODO FORMATIVO TARAPAQUEÑO (900 AC-900 DC)
}

\author{
Leonor Adán, ${ }^{1}$ Simón Urbina, ${ }^{2}$ Constanza Pellegrino ${ }^{3}$ y Carolina Agüero ${ }^{4}$
}

\section{* Introducción}

Resumen

Este ensayo aborda la relación entre arquitectura residencial y espacios de congregación en un conjunto de aldeas y asentamientos formativos ubicados en las quebradas de Tarapacá y Guatacondo, norte de Chile. Se analizan sus cualidades formales y su rol como inscripciones territoriales y contenedores sociales; su materialidad y organización interna; las prácticas sociales desarrolladas y el rol de estos espacios públicos en la experiencia cotidiana y el orden social. Se enfatiza la variabilidad, tanto formal como respecto de las acciones y usos desarrollados, de los espacios edificados amplios y de usos compartidos y, consecuentemente las diferencias de los actos congregacionales y públicos. Proponemos un análisis que amplía el uso de la arquitectura como indicador histórico cultural, integrando referentes de campos disciplinarios afines.

Palabras claves: arquitectura residencial - arquitectura pública - período Formativo - Tarapacá - Andes Centro-Sur. This paper concerns the relationship between residential architecture and gathering spaces in a group of Formative villages and settlements located in the Tarapacá and Guatacondo valleys of Northern Chile.

The attributes analyzed include the sites' formal characteristics and their role as territorial inscriptions and social containers, their materials and internal organization, and the associated social practices and the role of these public spaces in everyday experience and social order. We emphasize the variability, both in formal terms and with respect to the associated actions and usage of these open, constructed spaces and their shared use, and consequently, the differences in the congregational and public actions. We propose a frame of analysis that broadens the use of architecture as a historic-cultural indicator, integrating models from related fields.

Key words: residential architecture - public architecture - Formative period - Tarapacá - South Central Andes.

Recibido: febrero 2011. Aceptado: enero 2013.
Una de las cualidades significativas del Formativo tarapaqueño lo constituye el surgimiento de conjuntos residenciales amplios, o aldeas, que señalan una estructuración social novedosa, en los cuales habitarían grupos poblacionales mayores, en inmuebles complejos, diseñados para la realización de prácticas sociales cotidianas, domésticas, individuales, comunitarias, religiosas y públicas. Tal innovación tecnológica no es exclusiva de la región de Tarapacá: uno de los aspectos interesantes es la variabilidad arquitectónica en que ella tiene lugar, formando parte constitutiva del entramado de tradiciones arquitectónicas propias del área (Urbina et al. 2011, 2012). Estas tradiciones reflejan una forma de hacer o estilo tecnológico que comprende el manejo y empleo de ciertos materiales, el diseño de formas de planta predominantes, así como configuraciones espaciales características, además de un comportamiento espacial y cronológico, como señalamos a continuación.

En este trabajo nos enfocamos en las cualidades de la arquitectura doméstica comunitaria y de singulares espacios de congregación, de usos comunitarios o públicos, a partir del estudio de los sitios arqueológicos Caserones 1, Pircas 1, Ramaditas y Guatacondo I (Figura 1). De la diversidad de aproximaciones posibles para analizar la arquitectura prehispánica, los estudios arqueológicos regionales, en consonancia con los temas dominantes, han abundado en reflexiones de carácter histórico cultural, señalando las expresiones arquitectónicas como uno entre otros indicadores de influencias o tradiciones culturales,

\footnotetext{
1 Dirección Museológica Universidad Austral de Chile. Casilla 586, Valdivia, CHILE. Email: ladan@uach.cl

2 Facultad de Filosofía y Humanidades, Universidad Austral de Chile. Casilla 567, Valdivia, CHILE. Email: simon.urbina@uach.cl.
} 
de procesos económicos singulares del Formativo y también de las estrategias de sedentarización, que definen paradigmáticamente las condiciones del proceso de neolitización (Lumbreras 2006).

Este estudio, en cambio, busca ampliar las posibilidades interpretativas del registro arqueológico y con ello, el conocimiento de las sociedades formativas de Tarapacá (Uribe y Adán 2012). Nuestras reflexiones se apoyan teóricamente en enfoques centrados en la experiencia y la práctica social, como también en aquellos centrados en las cualidades ordenadoras de la arquitectura (Parker Pearson y Richards 1994a, 1994b; Blier 2006). Entonces, aquí queremos "pensar la arquitectura", ampliando históricamente nuestra comprensión de las edificaciones de uso público y comunitario, así como su relación con los espacios domésticos.

\section{* El período Formativo en Tarapacá}

En el norte de Chile, este período se plantea como una larga época de profundos cambios en la estructura social, el modo de vida y la cultura material. Generalmente, dichos cambios se han relacionado con un explosivo proceso de complejidad social y económica causado por el inicio de la producción de alimentos, ciertas especializaciones laborales o artesanales, mayores niveles de sedentarización, y consecuentemente, la adopción de la vida aldeana (Muñoz 1989; Núñez 1989).

En líneas generales, el Formativo en el Norte Grande se caracterizaría por elementos que innovan sobre las ancestrales tradiciones arcaicas de la costa y de la Puna, generando transformaciones económicas y sociales que alcanzan un momento clave hacia el 1000 AC (Núñez 1989). A partir de entonces, tanto los sitios habitacionales como funerarios contienen una gran diversidad material, lo cual daría cuenta de contactos e intercambios entre la costa, los valles, las tierras altas y el oriente

\footnotetext{
3 Programa de Magíster en Restauración Arquitectónica, Facultad de Estudios Patrimoniales, Universidad SEK. Av. Kennedy 9590, Depto. 202, Santiago, CHILE. Email: cony_france@yahoo.es.

4 Instituto de Investigaciones Arqueológicas y Museo, Universidad Católica del Norte. Gustavo Le Paige 380, San Pedro de Atacama, CP1410000, CHILE.Email: maguero@ucn.cl
}

amazónico, incluido el Noroeste Argentino (Núñez et al. 1975; Rivera 1975; Muñoz 1987; Núñez 1989; Núñez y Dillehay 1995; Ayala 2001). Tales contactos, a corta o larga distancia, estarían representados por la aparición de nuevas tecnologías como la cerámica, tejidos en fibra de camélidos domésticos, metalurgia en oro y cobre, y plantas cultivadas de origen foráneo entre las cuales se encuentran el maíz, las cucurbitáceas, los porotos y el algodón (Focacci 1974; Muñoz 1980; Santoro 1980, 1981; Dauelsberg 1985; Rivera 2005).

El ámbito inmueble en el que se desarrollaría este nuevo modo de vida estaría representado por arquitectura residencial, funeraria y ceremonial que enfatiza lo comunitario (Agüero et al. 2001; Romero et al. 2004; Núñez 2005). Espacios de congregación de las unidades domésticas o linajes se asociarían, además, con manifestaciones artísticas sobre soportes muebles e inmuebles (p.e., geoglifos, modelados en paredes de barro, grabados sobre piedra o postes de madera) de carácter icónico y simbólico explícito, los cuales se interpretan como distintos episodios de crisis e innovación sobre las estructuras familiares, generando las condiciones para el surgimiento de la desigualdad social y la centralización política (Rivera 1985; Núñez 1989; Muñoz 2004). Esta propuesta implicaría que los desarrollos formativos locales demostrarían una marcada integración con sistemas sociales basados en los tradicionales ideales andinos de una economía agrícola y ganadera, relaciones de reciprocidad, intercambio y complementariedad ecológica, permitiendo el surgimiento de élites legitimadas desde el plano religioso macrorregional y por su conexión con los núcleos civilizatorios de las tierras altas y, en especial, del altiplano (Rivera 1994; Núñez y Dillehay 1995).

Las investigaciones arqueológicas relativas a las tradiciones arquitectónicas formativas de Tarapacá han permitido una comprensión comparativa más detallada de sus manifestaciones en y entre distintos ambientes. Al analizar los asentamientos de la costa, las quebradas cercanas a la pampa del Tamarugal y las tierras altas, se ha definido un conjunto de modalidades constructivas que documentan los cambios propios de la transición Arcaico-Formativo, como innovaciones locales o zonales, que junto con la variable cronológica y la transferencia de conocimientos, tienen relación con ciertos cambios históricos y políticos ocurridos en el seno o entre unidades 


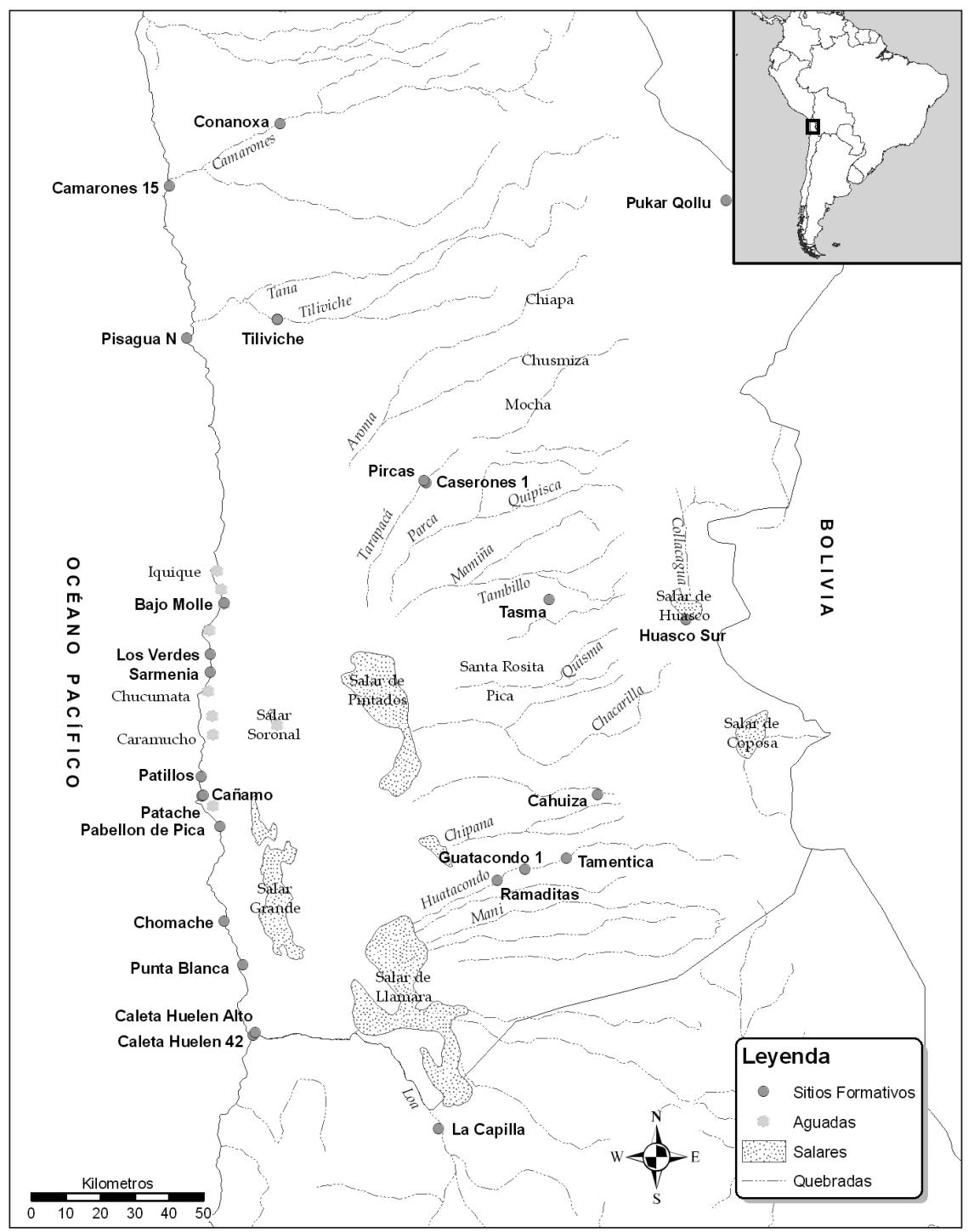

Figura 1. Localización de los asentamientos en la región de Tarapacá.

sociales que ocuparon la región cultural, que se configura como tal desde esta época (Uribe 2009; Urbina et al. 2011). Al respecto, hemos distinguido tres tradiciones arquitectónicas que presentan distribuciones y características especiales, a la vez que interactúan y reflejan una mayor diversidad de los desarrollos tecnológicos o "formas de hacer" de la arquitectura tarapaqueña.

Una primera modalidad está definida por la Tradición Arquitectónica en Piedra o Temprana, la cual presenta una distribución circumpuneña, configurando una práctica ar- quitectónica bien conocida y de larga data entre las comunidades cazadoras recolectoras. Se conforma por unidades aisladas o pequeños conglomerados de planta circular o de muros curvos, pisos semisubterráneos y entierros funerarios o fundacionales bajo los pisos domésticos. En la costa tarapaqueña posee un registro amplio desde el río Loa hasta la zona de Punta Patache (Urbina et al. 2011, 2012), con fechas que arrancan en el primer milenio AC.

Una modalidad innovadora y que expresaría la adopción de nuevos conocimientos, asociados al manejo de un 


\begin{tabular}{|c|c|c|c|c|c|c|c|}
\hline Sitio & $\mathbf{N}^{\circ}$ estructuras & $\begin{array}{c}\text { Superficie } \\
\text { construida }\left(\mathbf{m}^{2}\right)\end{array}$ & $\begin{array}{c}\text { Superficie acumulada } \\
\text { Plazas }\left(\mathbf{m}^{2}\right)\end{array}$ & Superficie (há) & $\begin{array}{l}\text { Densidad } \\
\text { edilicia }\end{array}$ & $\begin{array}{c}\text { Factor de } \\
\text { ocupación (\%) }\end{array}$ & $\begin{array}{c}\text { Factor de ocupación } \\
\text { suelo espacios } \\
\text { públicos }(\%)\end{array}$ \\
\hline Ramaditas & 83 & 2369.5 & 1148.0 & 9.23 & 9.0 & 2.56 & 48.45 \\
\hline Guatacondo 1 & 177 & 4215.1 & 1838.0 & 0.78 & 227.00 & 53.91 & 43.61 \\
\hline Pircas 1 & 562 & 6594.1 & 2058.0 & 89.89 & 6.25 & 0.73 & 31.21 \\
\hline Caserones 1 & 646 & 15996.2 & 3415.0 & 3.75 & 172.27 & 42.65 & 21.35 \\
\hline
\end{tabular}

Tabla 1. Índices arquitectónicos por sitio.

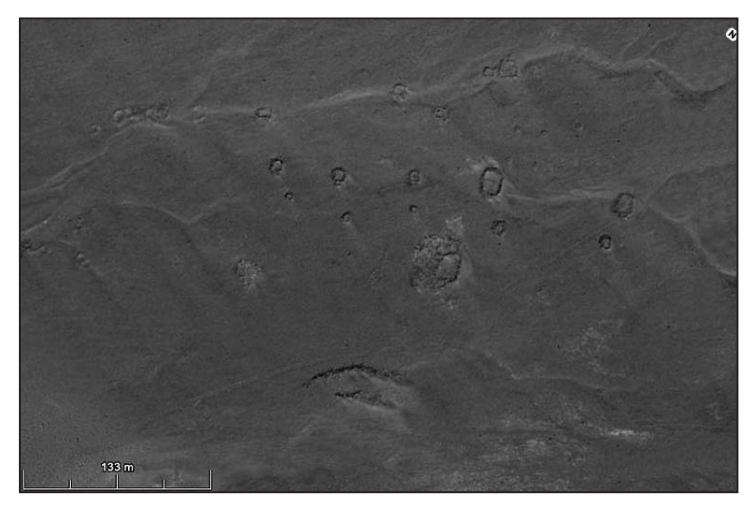

Figura 2. Pircas 1: Fotografía aérea (Fuente: Google Earth 2009).

material plástico como el barro, se encuentra en la que hemos llamado Tradición Arquitectónica de Oasis en Barro. Se distribuye en las regiones del Salar de Atacama y Tarapacá, y representa una tradición constructiva netamente formativa en sectores de oasis desérticos, la cual mantiene ciertos elementos de la tradición pétrea, como los muros curvos, las fundaciones con pilares de piedra o los pisos semisubterráneos. Es ejemplar en los oasis de San Pedro (p.e., Tulor) y en la quebrada de Guatancondo (p.e., Ramaditas y Guatacondo 1), con fechas que van desde $1000 \mathrm{AC}$ hasta $100 \mathrm{DC}$, aproximadamente. Se caracteriza por conjuntos muy aglutinados y densos de planta circular u ovoidal, infraestructura para el almacenaje comunal (pozos cavados), como práctica intensificada, techumbres extensas y sistemas de conectividad y protección contra el sol y el viento. Además, incluye espacios de congregación, al modo de plazas o grandes patios, en ciertas ocasiones ornamentados (paredes con modelados sobre barro/estuco) o con dispositivos centrales (monolitos).
En tercer lugar hemos identificado una Tradición Arquitectónica en Anhidrita o Caliche. Ésta se dispone en la sección inferior de la quebrada de Tarapacá (Núñez 1983) y en el río Loa, en la aldea de Quillagua (Cervellino y Téllez 1980). Representa la tradición tarapaqueña de más larga duración (600 AC-110o DC), y es singular por sus recintos de planta cuadrangular y conjuntos de traza ortogonal en ciertos casos. En la quebrada de Tarapacá se registran varias aldeas de este tipo, edificadas entre momentos clásicos del Formativo hasta el período Intermedio Tardío. Caserones es el caso más emblemático, abandonando el uso de la piedra, y agregando una trama de barrios que crea un escenario aldeano completamente nuevo en relación a las tradiciones anteriores.

\section{* Registro arquitectónico de Pircas 1, Caserones 1, Guatacondo 1 y Ramaditas}

La caracterización y análisis que presentamos se basa en el registro arquitectónico completo de los asentamientos estudiados. Para ello se aplicó una ficha de registro siguiendo los procedimientos propuestos por Castro y colaboradores (1993), metodología que ya hemos aplicado en diferentes áreas arqueológicas del Loa, San Pedro de Atacama y Tarapacá con el propósito de contar con resultados regionales comparables a partir de registros superficiales. Los registros en el campo se acompañaron de levantamientos y estudios planimétricos y croquis en la totalidad de los sitios, con especial énfasis en Caserones (Pellegrino 2011).

\section{Pircas I}

Este sitio se localiza en la terraza norte de la quebrada de Tarapacá a $1.300 \mathrm{~m} . \mathrm{snm}$ de acuerdo a las investigaciones 


\begin{tabular}{|c|c|c|c|c|c|c|c|c|c|c|c|c|c|c|}
\hline 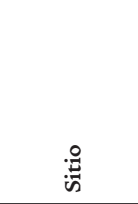 & 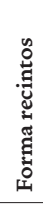 & 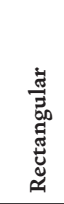 & 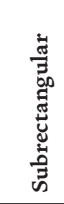 & 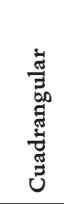 & 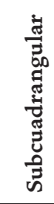 & 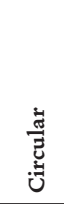 & 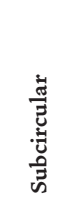 & 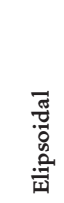 & $\begin{array}{l}\bar{J} \\
\overline{0} \\
0 \\
0\end{array}$ & 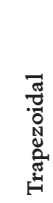 & 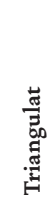 & 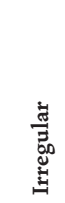 & 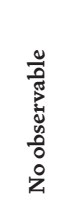 & స్ \\
\hline \multirow{2}{*}{ Ramaditas } & $\mathrm{n}$ & - & 2 & 1 & - & 14 & 9 & 5 & 24 & - & - & 28 & - & 83 \\
\hline & $\%$ & - & 2.40 & 1.20 & - & 16.86 & 10.84 & 6.02 & 28.91 & - & - & 33.73 & - & 100.00 \\
\hline \multirow{2}{*}{ Guatacondo 1} & $\mathrm{n}$ & 1 & 9 & 1 & 6 & 17 & 20 & - & 21 & - & - & 98 & 4 & 177 \\
\hline & $\%$ & 0.56 & 5.08 & 0.56 & 3.38 & 9.60 & 11.29 & - & 11.86 & - & - & 55.36 & 2.25 & 100.00 \\
\hline \multirow{2}{*}{ Pircas 1} & $\mathrm{n}$ & 26 & 6 & 12 & 2 & 122 & 57 & 173 & 10 & 7 & - & 145 & 2 & 562 \\
\hline & $\%$ & 4.62 & 1.06 & 2.13 & 0.35 & 21.70 & 10.14 & 30.78 & 1.77 & 1.24 & - & 25.80 & 0.35 & 100.00 \\
\hline \multirow{2}{*}{ Caserones 1} & $\mathrm{n}$ & 379 & 76 & 84 & 5 & 21 & 9 & - & 9 & 4 & 2 & 53 & 3 & 645 \\
\hline & $\%$ & 58.75 & 11.78 & 13.02 & 0.77 & 3.25 & 1.39 & - & 1.39 & 0.62 & 0.31 & 8.21 & 0.05 & 100.00 \\
\hline
\end{tabular}

Tabla 2. Distribución de formas de planta por sitio.

efectuadas por Núñez (1982, 1984), el sector más aglutinado del sitio se compondría de un total de 56 conjuntos arqueológicos, en el cual se registrarían estructuras habitacionales y de servicio, cementerios acotados, áreas ceremoniales delimitadas por muros periféricos, y áreas con fosos de ofrendas en las proximidades a las estructuras habitacionales y en espacios abiertos. También se identificarían geoglifos como círculos de piedras con un promontorio central, líneas paralelas, aserradas, líneas y círculos simples.

El registro efectuado identificó una superficie de 90 há con 562 estructuras en un patrón disperso con densidad de 6.3 estructuras por hectárea. La inversión de trabajo calculada mediante la suma de las superficies interiores arroja un total de $6.594 \mathrm{~m}^{2}$, de tal manera que el índice FOS ${ }^{5}$ señala que un $0.7 \%$ de la superficie total del asentamiento fue destinada a recintos (Tabla 1; Figura 2). Se documentaron cientos de estructuras de distintas características, por lo cual es evidente la existencia de más de un componente arquitectónico en el lugar. Otro elemento notable es la visibilidad mutua o intervisibilidad que se logra en el borde sur de Pircas con la aldea de Caserones, especialmente donde se concentran sus conglomerados más importantes (Núñez 1984: figs. 1 y 2).

5 Factor de Ocupación de Suelo (sensu Raffino 1990). Se estima calculando el total de la superficie construida (SC) que comprometen los recintos edificados respecto del total de la superficie del asentamiento.
Las estructuras de Pircas se forman de manera aislada, predominantemente, y también en conglomerados con subdivisiones internas. Otras corresponden a "geoglifos", alineamientos perimetrales a otras estructuras, amontonamientos de piedras, parapetos semicirculares aislados o adosados a bloques mayores y depresiones con hileras laterales que hoy se encuentran cubiertas por arena.

La distribución de las formas de planta indica el predominio de aquellas de muros curvos (64.4\%); se trata mayoritariamente de estructuras elipsoidales (30.8\%) y circulares (21.7\%) (Tabla 2). Le siguen aquellas de forma irregular (25.8\%), de difícil definición por el mal estado de conservación en el que se encuentran o el relleno de arena que las cubre. Por último, y en baja frecuencia, se encuentran los espacios rectangulares, cuadrangulares y sus derivados, los cuales alcanzan un $8.2 \%$ del total, con predominio de aquellas rectangulares cuya frecuencia no supera el 5\%. Consecuentemente, la planta dominante del conjunto es de forma subcircular e irregular con un trabajo de socavamiento previo.

La clasificación de los tamaños de planta permite apreciar una altísima presencia de pequeñas estructuras de menos de $5 \mathrm{~m}^{2}(60.1 \%)$. Las estructuras correspondientes a espacios domésticos o asociados a éstos, miden entre 5.1-20 $\mathrm{m}^{2}$ (29.5\%), comprometiendo 166 estructuras. Luego, se encuentra un pequeño conjunto de estructuras medianas y grandes de entre $20.1-60 \mathrm{~m}^{2}$, que pudieron servir de espacios habitacionales, patios, o bien, corrales. 


\begin{tabular}{|c|c|c|c|c|c|c|c|c|c|}
\hline Sitio & $\begin{array}{c}\text { Rangos de } \\
\text { tamaño }\end{array}$ & Hasta $5 \mathrm{~m}^{2}$ & $5.1-10 \mathrm{~m}^{2}$ & $10.1-20 \mathrm{~m}^{2}$ & $20.1-40 \mathrm{~m}^{2}$ & $40.1-60 \mathrm{~m}^{2}$ & Más de $60 \mathrm{~m}^{2}$ & $\begin{array}{c}\text { No } \\
\text { observable }\end{array}$ & Total \\
\hline \multirow{2}{*}{ Ramaditas } & $\mathrm{n}$ & 13 & 22 & 28 & 9 & 4 & 7 & - & 83 \\
\hline & $\%$ & 15.66 & 26.51 & 33.73 & 10.84 & 4.82 & 8.43 & - & 100.00 \\
\hline \multirow{2}{*}{ Guatacondo 1} & $\mathrm{n}$ & 30 & 54 & 57 & 26 & 3 & 3 & 4 & 177 \\
\hline & $\%$ & 16.95 & 30.51 & 32.20 & 14.69 & 1.69 & 1.69 & 2.26 & 100.00 \\
\hline \multirow{2}{*}{ Pircas 1} & $\mathrm{n}$ & 338 & 90 & 76 & 32 & 12 & 14 & - & 562 \\
\hline & $\%$ & 60.14 & 16.01 & 13.52 & 5.69 & 2.14 & 2.49 & - & 100.00 \\
\hline \multirow{2}{*}{ Caserones 1} & $\mathrm{n}$ & 160 & 141 & 142 & 94 & 54 & 46 & 9 & 646 \\
\hline & $\%$ & 24.77 & 21.83 & 21.98 & 14.55 & 8.36 & 7.12 & 1.39 & 100.00 \\
\hline
\end{tabular}

Tabla 3. Distribución de rangos de tamaño por sitio.

\begin{tabular}{|c|c|c|c|c|c|c|c|c|c|c|c|c|c|c|c|c|c|c|}
\hline & & \multicolumn{6}{|c|}{ Hilada } & \multicolumn{6}{|c|}{ Aparejo } & \multicolumn{3}{|c|}{ Materiales } & \multicolumn{2}{|c|}{ Ancho muro } \\
\hline \multicolumn{2}{|l|}{ Sitio } & Simple & Doble & Doble/ & Doble/ & $\mathrm{N} / \mathrm{O}$ & Total & Bústico & Reyestido & Rústico/ & Sedimentario & $N / 0$ & Total & Pied nol & Mortero & Otros & Min & Máx | p \\
\hline \multirow{2}{*}{ Ramaditas } & $\mathrm{n}$ & 14 & 34 & 6 & 4 & 25 & 83 & 1 & & 7 & 2 & 73 & 83 & $\mathrm{x}$ & $\mathrm{x}$ & $\mathrm{x}$ & 0.12 & 0.6 \\
\hline & $\%$ & 16.86 & 40.96 & 7.22 & 4.81 & 30.12 & 100.00 & 120 & & 8.43 & 240 & 67.95 & 100.00 & & & & & \\
\hline \multirow{2}{*}{ Guatacondo 1} & $\mathrm{n}$ & 41 & 12 & & 7 & 117 & 177 & & & & 2 & 175 & 177 & $\mathrm{x}$ & $\mathrm{x}$ & $\mathrm{x}$ & 0.12 & 1.1 \\
\hline & $\%$ & 23.16 & 6.77 & & 3.95 & 66.10 & 100.00 & & & & 112 & 98.87 & 100.00 & & & & & \\
\hline \multirow{2}{*}{ Pircas 1} & $\mathrm{n}$ & 233 & 59 & 27 & 4 & 239 & 562 & 128 & & & & 434 & 562 & $\mathrm{x}$ & $\mathrm{x}$ & $\mathrm{x}$ & 0.1 & 4.38 \\
\hline & $\%$ & 41.45 & 10.49 & 4.80 & 0.71 & 42.52 & 100.00 & 22.77 & & & & 77.22 & 100.00 & & & & & \\
\hline \multirow{2}{*}{ Caserones 1} & $\mathrm{n}$ & 245 & 30 & 226 & & 145 & 646 & 124 & 94 & & 159 & 269 & 646 & $\mathrm{x}$ & $\mathrm{x}$ & $\mathrm{x}$ & 0.07 & 157 \\
\hline & $\%$ & 37.93 & 4.64 & 39.98 & & 22.45 & 100.00 & 19.20 & 14.55 & & 24.61 & 41.64 & 100.00 & & & & & \\
\hline
\end{tabular}

Tabla 4. Características de los paramentos por sitio.

Finalmente, un $2.5 \%$ de espacios muy grandes han sido identificados como recintos de uso para la congregación cotidiana, ceremonial o pública. Se incluyen también en este porcentaje alineamientos perimetrales pétreos y geoglifos (Tabla 3).

Los recintos han sido edificados con piedras locales como andesita, basalto e ignimbrita. Predominan los muros de hilada simple (41.5\%), seguidos de muros dobles y dobles con relleno que en conjunto totalizan un 15.3\% (Tabla 4). Estos muros dobles sostuvieron en algunos casos, tal como se constató en los sondeos estratigráficos, material vegetal liviano para formar paramentos en altura. El uso de mortero solo se observa en ciertos recintos, no obstante, lo común es percibir el relleno de los muros dobles saliendo entre los bloques de piedra de mayor tamaño. El ancho máximo registrado en los muros es de $1.8 \mathrm{~m}$, mientras el alto máximo es de $0.8 \mathrm{~m}$. La presencia de vanos es difícil de definir mediante el registro arquitectónico superficial; sin embargo, y considerando la presencia de jambas, se logró identificar un conjunto de accesos, los que se localizaban en los recintos tanto de forma única en la estructura, como también dos vanos, en el caso de ciertas unidades arquitectónicas. 


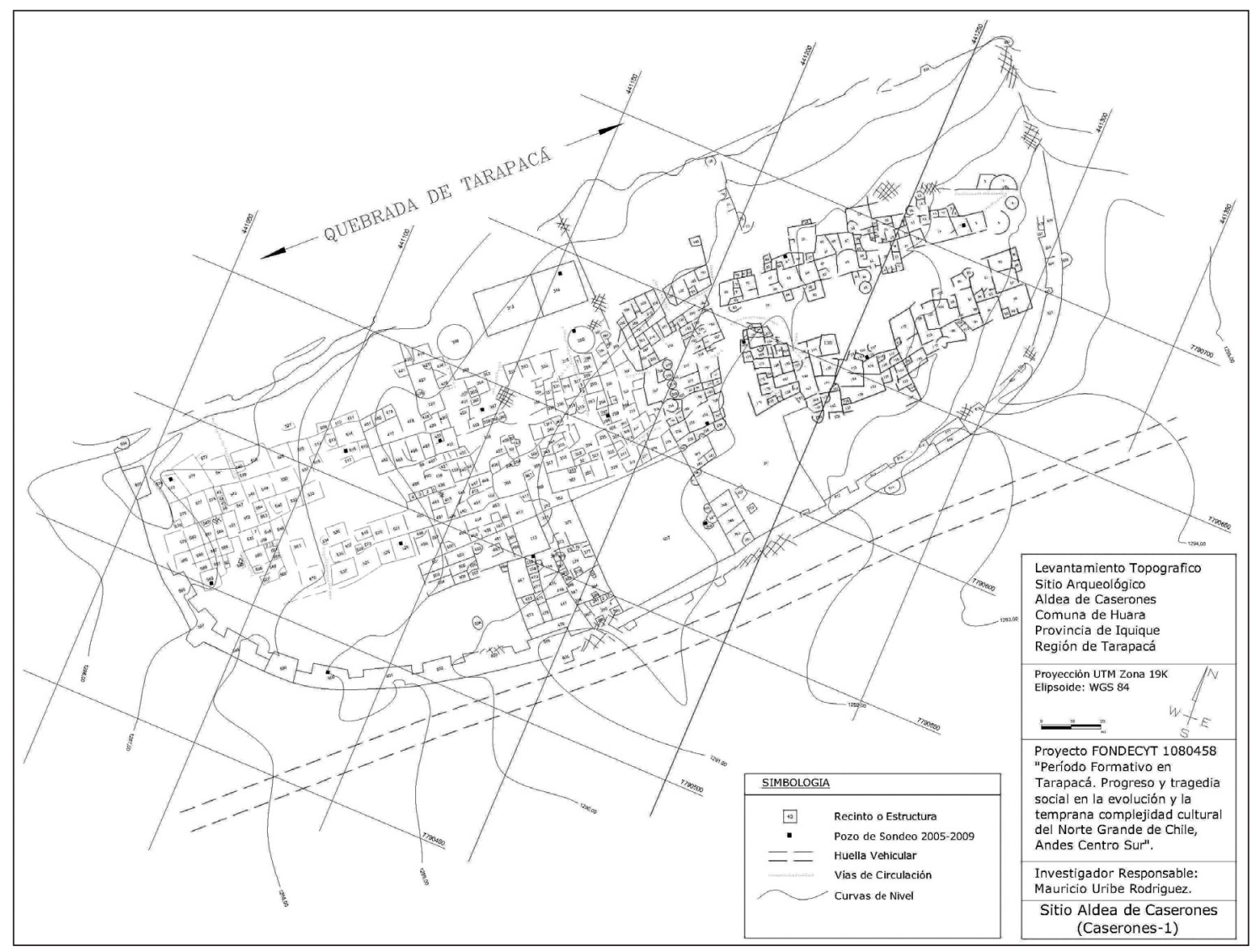

Figura 3. Caserones 1: Levantamiento topográfico y sectorización.

\section{Caserones 1}

Este asentamiento se localiza a $1.290 \mathrm{~m} . \mathrm{snm}$, en la terraza sur de la quebrada, y como hemos señalado, con visibilidad hacia Pircas (Núñez 1966, 1982). Se compone de 645 estructuras en un patrón aglomerado, edificadas sobre una superficie de 3.75 há, lo que señala un patrón muy concentrado de 172 recintos por hectárea. Se observa una edificación de $15.9 \mathrm{~m}^{2}$ y una ocupación constructiva de la superficie de la aldea o FOS cercana al $43 \%$ (ver Tabla 1).

La organización del asentamiento define tres conjuntos distinguibles por sus formas de plantas, la contigüidad de muros y las vías de circulación (Figuras 3 y 4 ). Al norte vemos dos sectores diferenciados por una vía de circulación longitudinal, al noreste aquel compuesto por los recintos 1 a 83, y al sureste, por los recintos 84 a 179 .
Un tercer conglomerado es el que ocupa la porción oeste del sitio, el que a su vez, también define subconjuntos en consideración a sus características. Así, vemos al centro un conjunto sumamente aglutinado conformado por los recintos 180 a 351, un sector contiguo con una disposición más longitudinal al sitio entre los recintos 354 y 504, y por último, un área organizada luego de una formación de túmulos de piedra y tierra, integrada por los recintos 511 al 593, que llega a unirse con el muro perimetral (Adán et al. 2007). Destaca en el sector oeste la existencia de dos plazas de diferente factura al norte y al sur del asentamiento. En la porción sur es posible visualizar el muro perimetral doble, que define hacia el sur una suerte de "fachada" de trazo regulary diseño "almenado".

La plantas son, en su mayoría, rectangulares, subrectangulares y cuadrangulares (84.3\%); siguen las plantas irregulares $(8.2 \%)$, y tan solo un $6.0 \%$ de las estructuras son de 


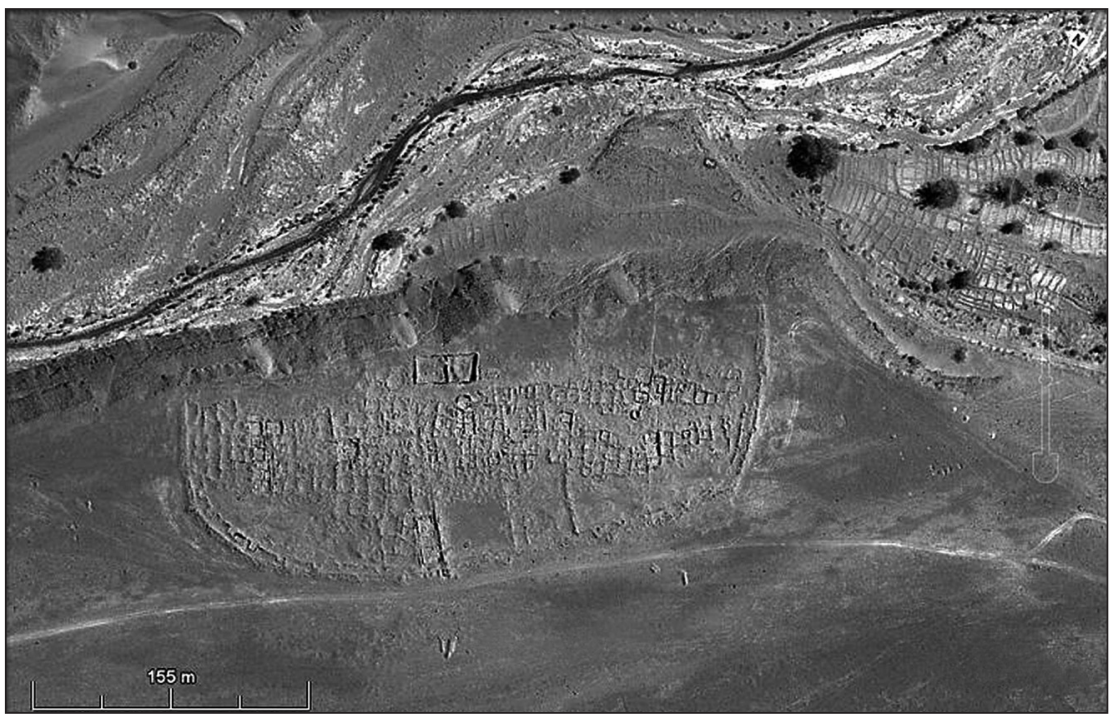

Figura 4. Caserones 1: Fotografía aérea (Fuente: Google Earth 2009).

planta circular o de muros curvos, las que pese a su escasa frecuencia son interesantes por su clara definición y diferencia del conjunto general (ver Tabla 2). Respecto de los tamaños (ver Tabla 3), el registro acusa una importante variabilidad; la mayor cantidad de recintos presenta dimensiones entre 5.1-20 $\mathrm{m}^{2}(43.8 \%)$, seguidos cercanamente por recintos menores a $5 \mathrm{~m}^{2}(24.8 \%)$. Entre los 20 y $40 \mathrm{~m}^{2}$ se agrupan 148 estructuras (22.9\%), al igual como ocurre con aquellos de más de $40 \mathrm{~m}^{2}$ (7.1\%). Considerando la frecuencia de estructuras entre $5.1-20 \mathrm{~m}^{2}$ se infiere un mínimo de unidades habitacionales cercano a 283 estructuras.

Los paramentos se construyeron en bloques de caliche o anhidrita (ver Tabla 4), con algunos bloques seleccionados de andesita y basalto en la sección inferior de muros, a modo de fundaciones. Un dato interesante es la presencia de grandes piedras usadas como pilares estructurales, así como muchos postes de madera configurando parte integral de los muros, rasgo presente en los diversos conjuntos de la aldea. Se observan muros simples (38.5\%), dobles, y dobles con relleno, los cuales alcanzan una proporción algo mayor al 40.2\%. Entre estos últimos dominan los muros dobles con relleno (35.5\%), lo que indica una mayor inversión de energía en la edificación de ciertos recintos. El registro de vanos, solo considerando como seguros aquellos que presentan elementos como jambas, alféizares y dinteles, elevan el número de unidades a 112, entre las que se cuentan accesos, ventanas y hornacinas.

\section{Ramaditas}

Más al sur, en la quebrada de Guatacondo, se localiza el sitio Ramaditas (Rivera et al. 1995-96; Martindale 2005; Rivera 2005). Los estudios efectuados por Rivera la describen como una aldea de 3 há compuesta por tres conjuntos arquitectónicos -un montículo, estructuras domésticas individuales y una importante área dedicada a campos de cultivo (Rivera 2005)-. Se ubica en las proximidades de un extenso sistema agrohidráulico al norte del curso inferior de la quebrada de Guatacondo, y $8 \mathrm{~km}$ al suroeste de las minas de cobre del cerro Challacollo (Graffam et al. 1996).

El asentamiento se emplaza a $1.100 \mathrm{~m} . \mathrm{snm}$, y se compone de 83 estructuras distribuidas en 9 há (Figura 5 a y b). La superficie construida intramuros es de $2.369 \mathrm{~m}^{2}$, de tal manera que la ocupación del suelo alcanza un $2.6 \%$ de la superficie del conjunto (ver Tabla 1). El asentamiento compromete conglomerados edificados distantes entre sí, con recintos de mayor tamaño, a modo de patios o plazas, otros más pequeños en su contorno y vías de circulación a modo de pasillos, además de otros recintos aislados. 


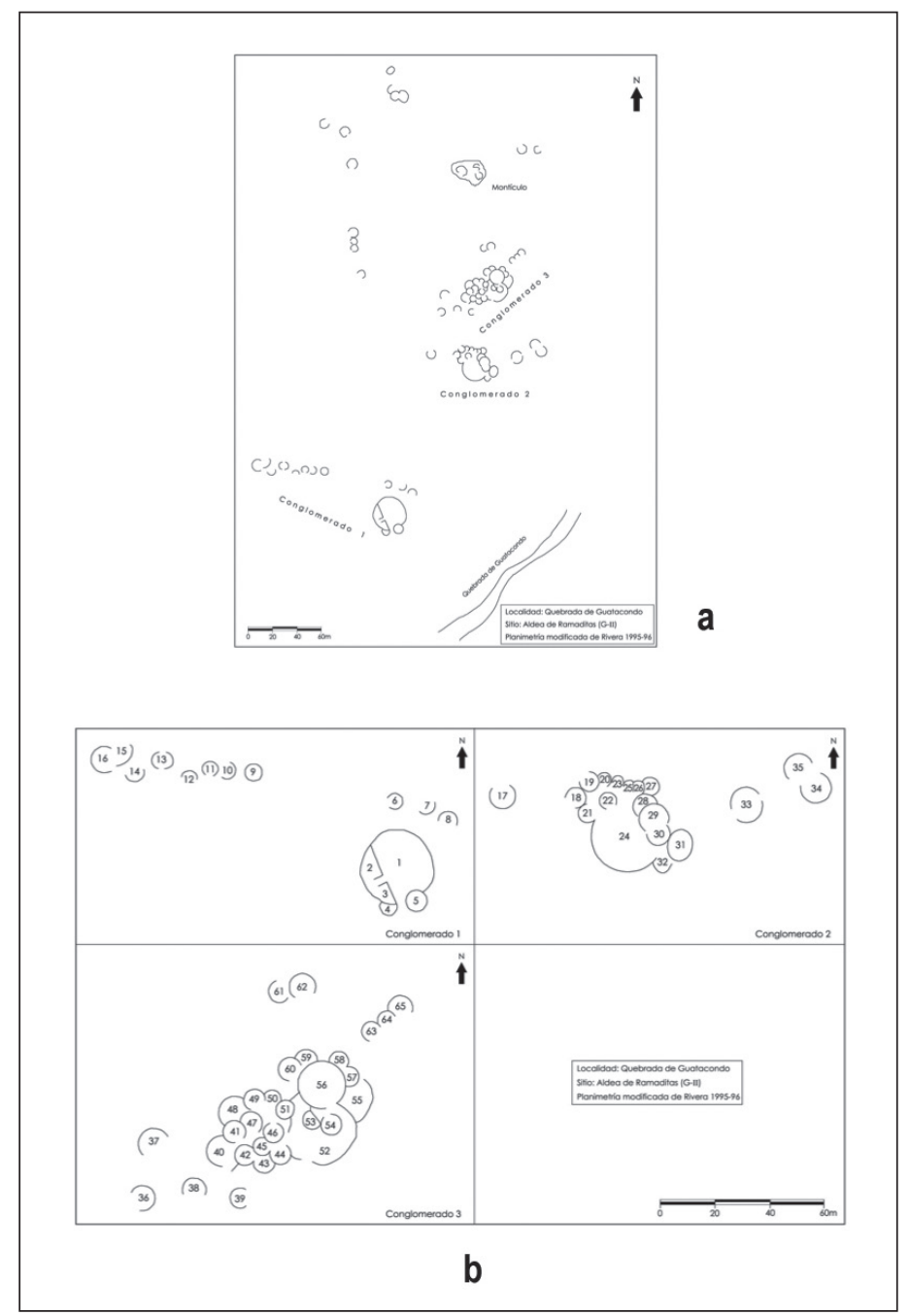

Figura 5. Ramaditas. a) Planimetría; b) Croquis de los Conglomerados 1, 2 y 3.

Las plantas de los recintos fueron socavadas y en su construcción se privilegiaron los muros curvos (62.63\%), y dentro de éstas las ovales con una frecuencia cercana al $29 \%$, seguidas por aquellas de forma circular (16.86\%) (ver Tabla 2; Figura $6 a$ y b). Las plantas irregulares (33.73\%), usualmente configuran espacios entre recintos, vestíbulos o vías de circulación cuyas formas pueden ser compuestas o poligonales. Destaca la relativa ausencia de plantas con ángulos rectos (rectangulares, cuadrangulares), las cuales tienen una mínima representación. Los tamaños registrados oscilan entre $1.52 \mathrm{~m}^{2}$ y $489.51 \mathrm{~m}^{2}$, ubicándose un $60.24 \%$ en el segundo y tercer rango de tamaño $\left(5-20.1 \mathrm{~m}^{2}\right)$, mientras un $15.66 \%$ lo hace en el primer rango $\left(0-5.1 \mathrm{~m}^{2}\right)$. Es significativa la ocurrencia de estructuras (8.43\%), en el rango de plantas con superficies mayores a $60.1 \mathrm{~m}^{2}$ (ver Tabla 3 ).

Los muros fueron levantados con barro húmedo, como adobones, mezclados con piedras y argamasa también de barro. Se detectaron mayoritariamente muros dobles, dobles con relleno o que presentan en alguna sección del muro estas características (53\%) (ver Tabla 4). La piedra, los adobes irregulares de barro y el mortero de barro utilizado con mayor o menor cantidad de inclusiones, han sido los elementos principales de la arquitectura de Ramaditas. Aunque gran parte del sitio combina estos 


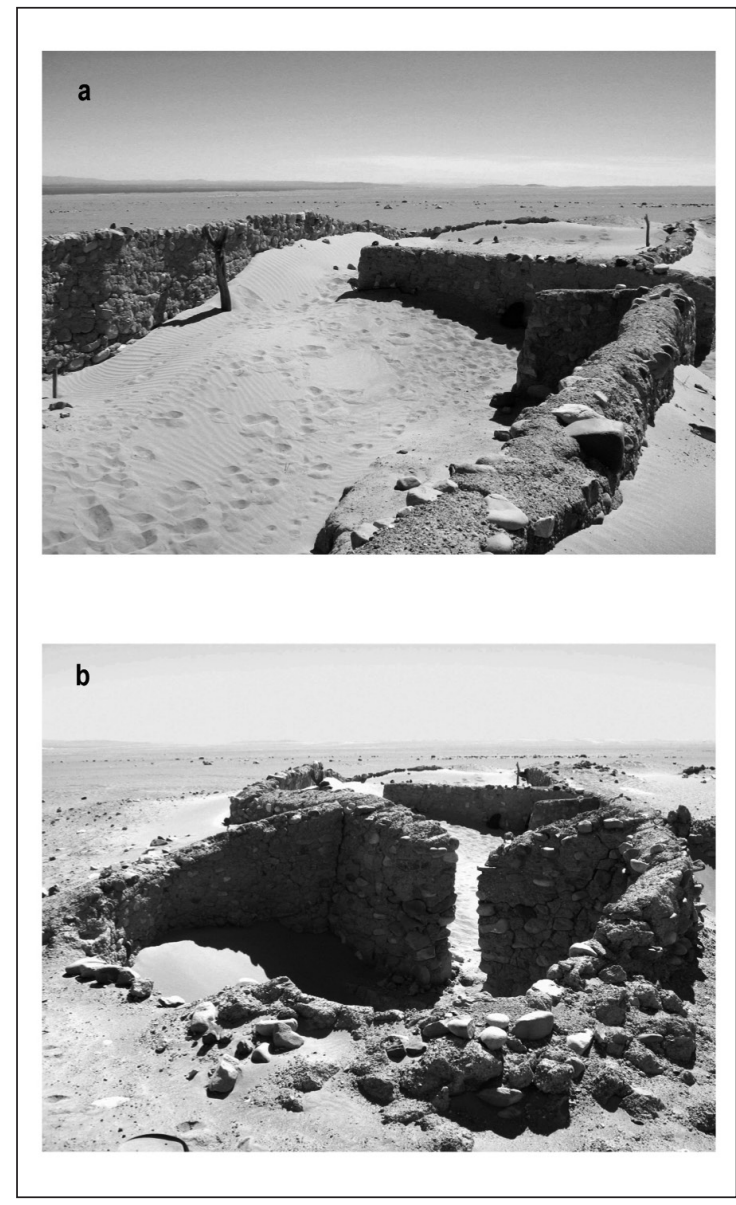

Figura 6. Ramaditas. a) Conglomerado 1, estructura 3; b) Conglomerado 1, estructura 4.

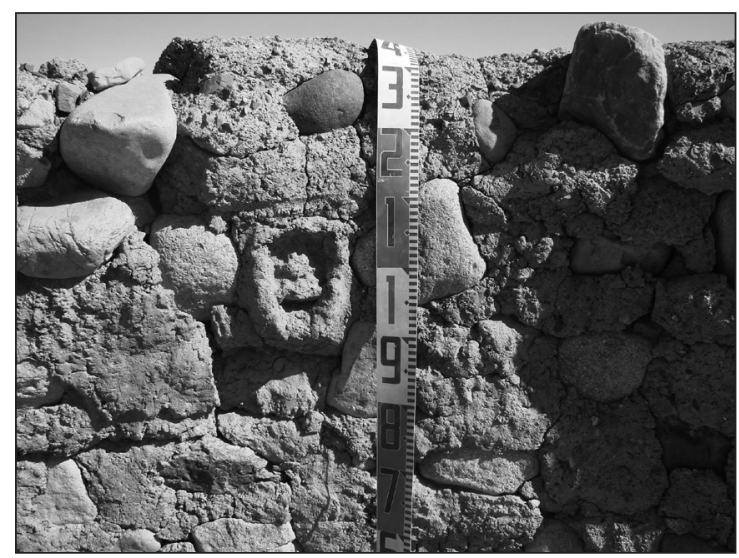

Figura 7. Ramaditas: Cara modelada en fresco sobre el muro interior de la estructura 3.

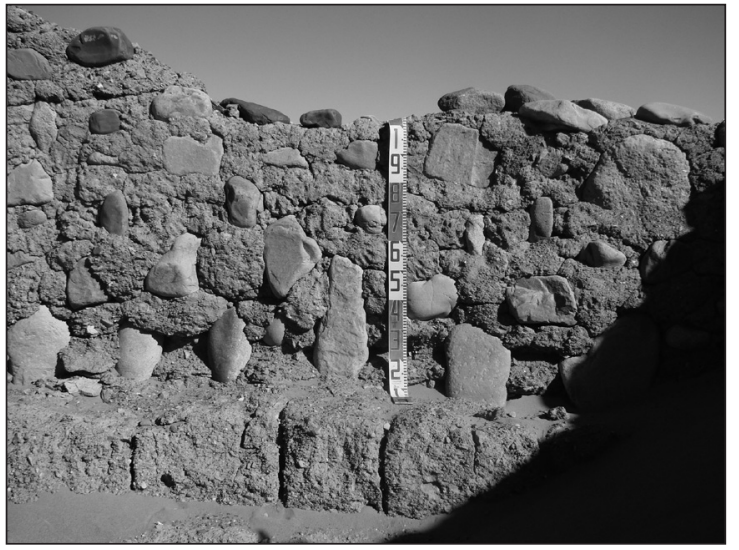

Figura 8. Ramaditas: Poyo o banqueta contigua al muro.

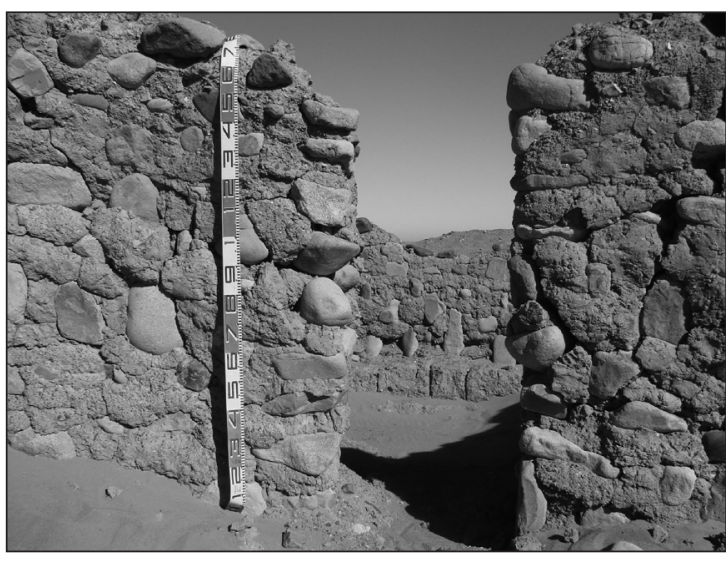

Figura 9. Ramaditas: Vano y banqueta vista desde la estructura 5.

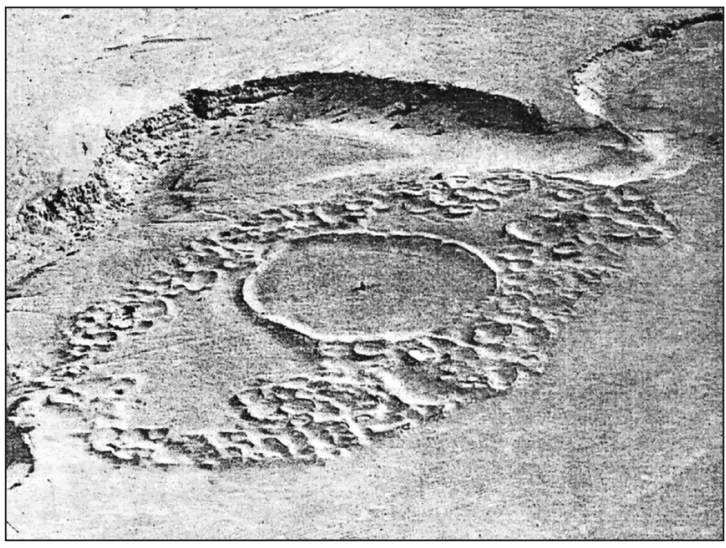

Figura 10. Guatacondo: Fotografía aérea (Fuente: Meihgan 1980).

84 \begin{tabular}{l|l}
$\mathrm{N}^{\circ} 45 / 2013$ \\
ESTUdios ATACAMEÑos \\
Arqueología y Antropología Surandinas
\end{tabular} 


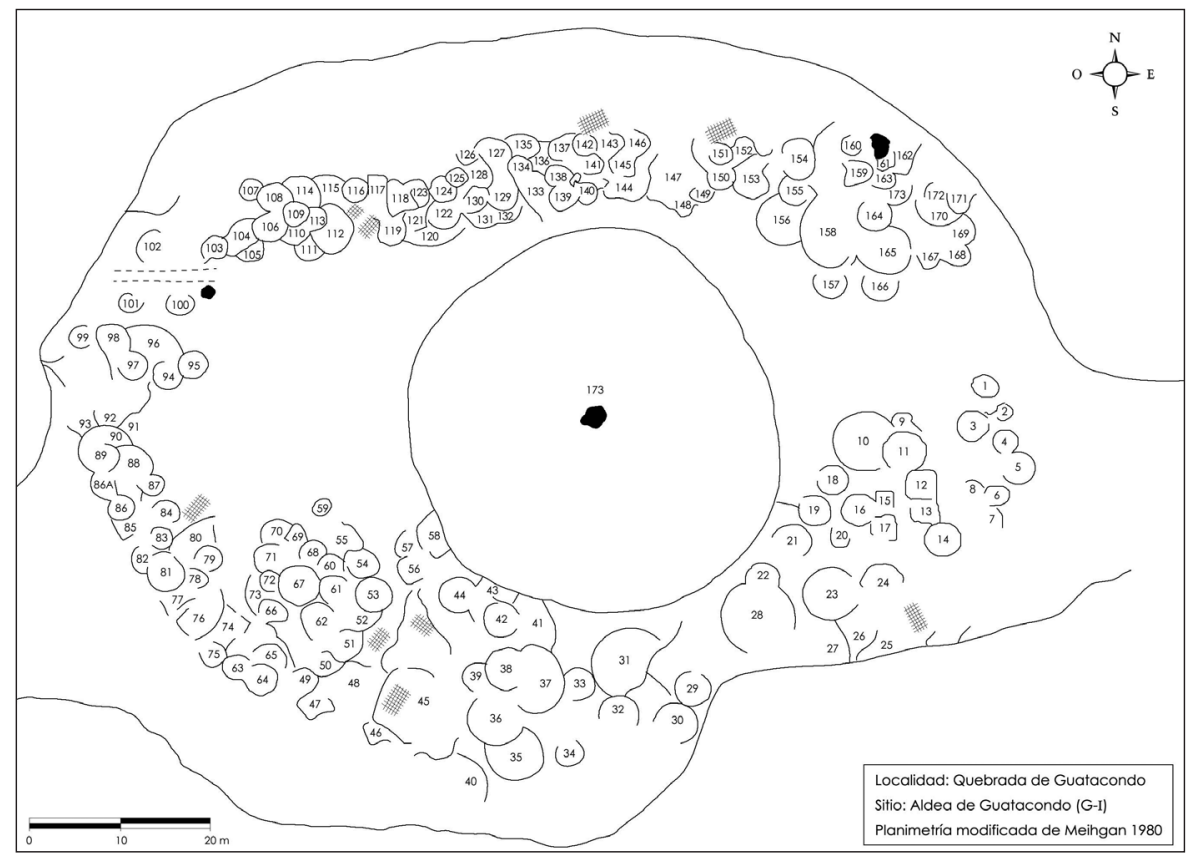

Figura 11. Guatacondo: Planimetría.

elementos, y han tendido a ser los elementos constructivos generalmente destacados, debe mencionarse que un $18.07 \%$ de las estructuras han sido construidas exclusivamente en piedras y corresponden a aquellas dispersas en torno a los conglomerados 1 y 2. Como en Caserones, se encuentran restos de maderas usados como postes para sostener las techumbres (Figura 6a).

La condición plástica en la que fueron levantados los muros, junto a porciones de muros que presentan un enlucido de barro, permitieron el diseño de diversas figuras, lineales o figurativas, emplazadas en partes claramente visibles de las unidades (Figura 7). Igualmente se observó en el interior de algunos recintos el uso funcional del socavamiento de la superficie mediante la generación de un poyo o banqueta contigua (Figura 8). En los paramentos se identificaron también las improntas de apoyo de vigas sobre los cabezales de éstos, usadas para contener la techumbre.

Pudimos identificar un número significativo de vanos, cuyos elementos mejor representados fueron las jambas líticas. También se registraron alféizares, en ciertos casos como escalinatas, y dinteles compuestos de ramas paralelas, como ocurre con una ventana en la estructura 17. Es significativo el hecho de que no se encuentren en forma mayoritaria dinteles en puertas y accesos a las estructuras (Martindale 2005) (Figura 9).

\section{Guatacondo 1}

Este asentamiento, denominado Guatacondo 1 por Mostny (1970), se encuentra localizado en la misma quebrada, $12 \mathrm{~km}$ más al interior y a 1.379 m.snm se compone de una gran estructura central, o plaza, que todavía conserva un eminente monolito de piedra al centro. Los recintos que configuran la aldea se distribuyen en torno a este espacio edificado central, evidenciando el carácter ordenador de esta estructura (Figuras 10 y 11 ).

El conjunto se conforma por $177^{6}$ recintos en una superficie de 0.78 ha, señalando la más alta densidad ocupacional de los sitios analizados, con 227 estructuras por hectárea de terreno. La superficie intramuros calculada es de $4.215 \mathrm{~m}^{2}$,

${ }^{6}$ La diferencia con los datos consignados por Meighan (1980) se deba probablemente a condiciones de conservación y avance de la cobertura de arena por acción eólica. Nuestro registro fue efectuado el año 2009 . 
de tal manera que las estructuras ocupan más de la mitad del área interna de la aldea (FOS: 53.9\%; ver Tabla 1).

Los paramentos fueron levantados con adobones de barro, además de piedras, aunque en su aspecto general, en comparación con Ramaditas, destaca la preeminencia del barro. Predominan los muros simples (23.16\%), siendo menos frecuentes los muros dobles y dobles con relleno (10.7\%) (ver Tabla 4). Las plantas fueron igualmente socavadas, y es posible que esa misma tierra haya sido usada para levantar los muros. En este patrón conglomerado, en torno a la plaza central, dominan las formas circulares e irregulares con una frecuencia de $32.8 \%$ y $55 \%$, respectivamente (ver Tabla 2 ).

Los tamaños oscilan entre $0.23 \mathrm{~m}^{2}$ y $1.838 \mathrm{~m}^{2}$, concentrados en su mayoría (62.7\%) en el segundo y tercer rango de tamaño $\left(5-20.1 \mathrm{~m}^{2}\right)$; mientras un $16.9 \%$ se ubica en el primer rango $\left(0-5.1 \mathrm{~m}^{2}\right)$, y de forma similar, con un $14.7 \%$, edificios con tamaños entre $20,1-40 \mathrm{~m}^{2}$. Destaca la escasa presencia de estructuras en el rango de mayor tamaño, sobre 60,1 $\mathrm{m}^{2}$, (1.7\%) (ver Tabla 3). Las habitaciones, que Meighan (1980) ubica acertadamente en el rango 4-20 $\mathrm{m}^{2}$, representarían aproximadamente 110 unidades del total $(n=177)$. Espacios entre recintos o vías de circulación surgidas del crecimiento de los conglomerados también son evidentes a través de la presencia de espacios irregulares de diversos tamaños (55.4\%). Difícil definición se observa en el registro de vanos dentro de la aldea, no obstante, en el caso de la estructura central se registran cuatro accesos -sin elementos como jambas-, cuyos anchos oscilan entre 0.6 y $1.3 \mathrm{~m}$, y marcan evidentes orientaciones cardinales $\left(92^{\circ} \mathrm{E}, 133^{\circ} \mathrm{SE}, 167^{\circ} \mathrm{SE}\right.$ y $\left.290^{\circ} \mathrm{NO}\right)$.

\section{* Nuevas aldeas en los bosques de prosopis: INSCRIPCIONES TERRITORIALES Y CONTENEDORES SOCIALES}

El desarrollo de aldeas en los valles de Tarapacá ha supuesto la construcción de conjuntos arquitectónicos complejos, como los que hemos descrito, en los que se integra arquitectura propiamente doméstica con otra de carácter público o congregacional. Para el caso de la llamada arquitectura doméstica o residencial seguimos las observaciones propuestas por Aldenderfer y Stanish (1993: 2) entendiéndola como un concepto empírico que integra "those structures, facilities, activity and work areas, and artefacts that are associated with the anthropological household". La operacionalización del concepto de arquitectura pública, en cambio, resulta más compleja. En este caso, nos han resultado útiles las indicaciones de Nielsen (2006) quien identifica aquellos espacios públicos como compuestos por una diversidad de formas arquitectónicas con diferentes funcionalidades, entre los cuales las "plazas" propiamente tales constituyen una de sus variantes. El mismo autor se ha referido a espacios de congregación social, eludiendo la oposición muy occidental de lo público con lo privado, cuya transposición a las sociedades andinas resulta evidentemente riesgosa. Consecuentemente, en este trabajo usamos indistintamente los términos espacios de congregación social o públicos, aunque reconocemos la complejidad inherente de usar el término público, principalmente por su asociación con dinámicas y situaciones de representación del poder político, como la delegación de la representación en ciertos actores, nociones que están evidentemente impregnadas de nuestro ideario occidental e ilustrado (Chartier 2003: 33-40). Estas observaciones nos permiten atender la variabilidad en los usos-funciones, en las prácticas sociales e ideas relacionadas de las comunidades que ocuparon las diferentes arquitecturas para la congregación social que los asentamientos tarapaqueños documentan.

En este contexto, las aldeas tarapaqueñas constituyen evidentes formas arquitectónicas para la residencia agrupada en diferentes maneras, de unidades domésticas, familias y conglomerados sociales. Es significativo que esta arquitectura doméstica es creada en estrecha relación con diferentes espacios arquitectónicos para la congregación social, configurando una particular interacción o dialéctica entre la práctica social y esta singular expresión de la cultura material que define la arquitectura.

Ya antes hemos propuesto un enfoque que asume el rol activo de la cultura material, así como la experiencia e interacción que se genera entre quienes crean y habitan estos artefactos, para el caso de la arquitectura formativa de San Pedro de Atacama (Adán y Urbina 2007). En este caso, es significativo que el surgimiento de ciertas formas arquitectónicas se relacione con el desarrollo de actividades rituales, especialmente al tratamiento de sus muertos y a expresiones de culto a los antepasados?. Tal situación

\footnotetext{
7 Notemos la existencia de evidencias arquitectónicas en el período
} 
es similar a lo observado en el sitio Caleta Huelén 42, en la desembocadura del río Loa (Zlatar 1983; Urbina et al. 2012). En este sitio, hacia el $2000 \mathrm{AC}$, sus antiguos habitantes entierran a sus muertos bajo el piso de sus habitaciones y construyen una de las más tempranas evidencias de arquitectura lítica, para servir de morada a sus difuntos, fijando en el espacio, no solo cuerpos y arquitectura, sino también su memoria. Hoy sabemos que esta tradición arquitectónica costera, vinculada a prácticas fúnebres habría tenido una significativa extensión litoral, entre el Loa y Taltal en los sitios de Abtao y Los Bronces, este último con fechas cercanas a 3500 AC (Contreras et al. 2007; Berenguer 2008). Es así como la inusual e innovadora tecnología de la arquitectura, se "promociona" en espacios de fuerte significación social en los que se crea y actualiza el sentido de comunidad, comunidad imaginada, al decir de Anderson (1993), en la que se habita en ese lugar/tiempo con otros distantes geográficamente, algunos muertos y otros por nacer (Urry 1991).

Unos mil años después, en torno a los bosques de Prosopis, comienzan a levantarse complejos aldeanos de diferente evolución. Sus emplazamientos señalan un territorio transitado y ocupado durante siglos por cazadores recolectores, a la vez que enfatiza la orientación de estas aldeas hacia los bosques, manteniendo una estrecha relación con los ámbitos costeros. Pueblos recolectores encantados con sus bosques e incorporando innovaciones agrícolas, lo cual nos recuerda los términos de Frazer, al señalarnos que:

“[...] también los espiritus arbóreos hacen prosperar las cosechas. Entre los mundaris, hay un bosque sagrado en cada aldea y las deidades del bosque tienen la responsabilidad de las cosechas, siendo especialmente festejadas en todas las grandes fiestas agrícolas"' (1995 [1890]: 152).

Las aldeas que analizamos se localizan en las quebradas de Tarapacá y Guatacondo y cuentan con dataciones entre los años 600 AC y 900 DC, señalando contemporaneidad al menos hacia el $100 \mathrm{AC}$. Todas ellas se encontraban

Arcaico en momentos mucho más tempranos para los Valles Occidentales y para la región de Tarapacá. Es útil destacar, además, el llamado de atención de Whitelaw (1994) sobre la complejidad social y simbólica en los espacios domésticos de grupos cazadores recolectores. asociadas a campos de cultivo, apenas visibles hoy en la superficie, y a los bosques de Prosopis. Del conjunto estudiado, y desde nuestro punto de vista, resulta evidente que uno de los cambios más relevantes es esta nueva forma de habitar y relacionarse con el espacio, en que ciertas prácticas domésticas se fijan espacialmente, tanto por la continuidad que tienen en el tiempo como por el hecho de que los lugares en que ellas se desarrollan, se edifican. En términos materialistas, es claro que estas nuevas prácticas o habitus, entre las que el manejo de los por ahora estables recursos silvestres que proveen los bosques, como asimismo las actividades agrícolas y el pastoreo, constituyen la base económica de un nuevo orden social en el que se modifica la experiencia y la materialidad, a la vez que se reorganiza la unidad doméstica. Esta vivienda fijada, definida por arquitectura inmueble, crea y posibilita el surgimiento de un nuevo espacio doméstico, donde "el hacer" en torno a una vivienda cobra importancia.

Al ver la variabilidad de los sitios analizados, notamos que en Pircas 1 el dominio de las estructuras aisladas y su menor tamaño dan cuenta de una situación transicional, pues si bien sus características constructivas corresponden a aquellas descritas para momentos Arcaicos, y en efecto hay fechas de estos momentos, ocurre un proceso de aglutinamiento que pese a su dispersión permite su definición como un conjunto arquitectónico. Sea que exista continuidad directa o no, cuestión que necesita mayor investigación, hay una evidente apropiación de ese pasado constructivo por parte de las poblaciones formativas, lo cual obedece probablemente a razones prácticas relativas a la mantención de un modo de vida como también a la posibilidad de acceder a los beneficios simbólicos de habitar espacios previamente ocupados (Hodder 1994: 77).

Varios de los conglomerados que encontramos en los sitios están definidos por un recinto más amplio y de uso común, con estructuras de tamaño variable asociadas, y cuyos accesos, al menos en el caso de Ramaditas, convergen a este espacio central, definiendo un patrón de arquitectura doméstica nuevo en la región, en el que destaca, además de la fijación espacial y la diversidad funcional, una intención en la permanencia y cierta vocación de monumentalidad. Un rasgo interesante detectado en Ramaditas, es la presencia de poyos o banquetas interiores dispuestas en el proceso constructivo del sitio, que hace ver, al menos en una mínima parte, la sitting society que 
reseña Ingold $(2004: 323)^{8}$, con los cambios posturales y cognitivos que ello significa, asociados a una percepción más sedentaria del mundo.

Los conjuntos totales adquieren en el paisaje las cualidades de inscripción y continente. Tanto por la materialidad con la que fueron edificados y la durabilidad que ello les otorga, como por la monumentalidad de algunos de éstos, constituyendo verdaderos hitos culturales y paisajísticos hasta nuestros días. La misma cualidad y práctica de inscripción se reproduce a nivel intrasitio, como ocurre en Ramaditas, donde las superficies de los muros fueron igualmente inscritas con improntas de manos y rostros sobre los adobones de barro. De la misma época son también algunos de los geoglifos y petroglifos conocidos para el área, como Cerro Pintados, Cerro Unitas y Tamentica, señalando la práctica de inscribir hitos - relatos - en el territorio habitado. Como señala De Certeau (2007: 129-134), es a través de las prácticas que ocurre el habitar en lugares y espacios que encuentran su configuración en recorridos y mapas. Es esta habitabilidad la que posibilita la invención de lo cotidiano o de un nuevo cotidiano. Esta narrativa espacial o "invención de memoria" a través de estos lugares inscritos debe concebirse ante todo como una acción creadora, que para el caso que analizamos crea un espacio culturalmente compartido, similar a las regiones o distritos definidos por Lynch (2000) en su obra sobre las imágenes, partes y formas de las ciudades. Las aldeas formativas así vistas, constituyen contenedores materiales y sociales, sumándose en Caserones 1 un nuevo gesto constructivo en el muro perimetral con contornos claros y bien definidos, marcando un límite físico como perceptual. Estos espacios construidos, con dinámicas internas imbricadas y bien segmentadas, como queda reflejado en el diseño celular de Guatacondo, articulan, por una parte, un interior que es creado y crea una

\footnotetext{
8 Ingold integra los postulados del diseñador Caplan quien afirma que: "[...] a chair is the first thing you need when you don't really need anything, and is therefore a peculiarly compelling symbol of civilization' ( $\mathrm{Ca}$ plan 1978: 18). Nothing however better illustrates the value placed upon a sedentary perception of the world, mediated by the allegedly superior senses of vision and hearing, and unimpeded by any haptic or kinaesthetic sensation through the feet" (2004: 323). Obviamente los poyos de los que hablamos no corresponden exactamente a las sillas que se describen, destacándose la ausencia de individualidad y seguramente su versatilidad funcional como repositorio de objetos.
}

nueva significación para el espacio doméstico, similar al espacio existencial definido por Norberg-Schulz (1975), mientras que junto con ese espacio existencial se delimita un exterior, generando un landmark o punto de referencia considerado externo para el observador (Lynch 2000). Estas nuevas aldeas permiten la organización y reproducción de un nuevo orden social tanto para sus moradores como para quienes no son sus habitantes, recordándonos las cualidades de inclusión/exclusión de todo espacio construido y limitado, en especial aquellos connotados como espacios públicos o de congregación, y el vértigo de los que no logran entrar a la plaza, y por tanto, no son vistos (Rosaldo 1999).

Esta cualidad de inscripción territorial, posiblemente también mediante otras prácticas y materialidades, se desarrolla en el caso de esta arquitectura por un ejercicio congregado de un número significativo de individuos, que en algunos casos como en la estructura mayor de Guatacondo o el muro perimetral del Caserones debió convocar significativa fuerza de trabajo, implantación de un diseño, por simple que éste parezca, coordinación grupal y probablemente especialistas de la acción. Estos espacios así edificados permiten la construcción de narrativas espaciales de significación grupal, articulando y permitiendo la definición de identidades e historias con referentes espaciales concretos, connotando de manera compleja el paisaje de los valles tarapaqueños.

\section{* Materialidades y ORganización espacial}

En su clásico Manual de Etnografía, al referirse a la alfarería, Mauss indica que:

"[...] en el estudio de las distintas clases de alfarería se hará entrar en principio a las piezas simplemente secas al sol. El adobe es alfarería; el conjunto de las fortificaciones de Marrakech no es más que un inmenso cacharro secado al sol" (2006: 66).

Entre las aldeas estudiadas, registramos variedad de materiales constructivos, diseños y rasgos que se expresan diferencialmente. En algunos casos es posible distinguir ciertos principios que comparten algunos o todos los conjuntos, que apuntan a la definición de cierto estilo constructivo y sus variaciones, propio del Formativo tarapaqueño. 
Respecto de la materialidad en la construcción de los asentamientos, Ramaditas y Guatacondo dan cuenta del conocimiento y manejo de las propiedades del barro, que resulta de la experiencia del paisaje que habitan, que en las prácticas agrícolas requiere el control preciso del agua en la inundación de los campos. En ambos, se recurre al empleo del barro, combinado con piedras, como piezas constructivas. Estos adobones o piezas, cuya agregación levanta los muros, se disponen en estado plástico, para finalmente ser secados o "cocidos" al sol (Lévi-Strauss 1986), permitiendo en esta transformación la creación del espacio doméstico y su habitabilidad. La tradición arquitectónica en barro tiene aquí sus primeras evidencias para la región, marcando una distancia tecnológica con la arquitectura lítica conocida desde el Arcaico, e instalando en ellas las estructuras para la congregación más amplias del conjunto analizado. Se añade el uso de grandes maderos a modo de postes que permitirán sostener las techumbres; estas últimas con materiales vegetales livianos del entorno.

Pircas 1 y Caserones 1, en cambio, son edificadas con piedras. La primera siguiendo el patrón Arcaico usa el material lítico local, añadiendo el uso de paramentos livianos de material vegetal. Caserones, por su parte, se edifica con bloques recortados de los mismos materiales, o caliche, que se despejan desde el lugar del asentamiento. En Guatacondo y Ramaditas se cava para levantar y obtener el barro, en Caserones se despeja para la obtención del material constructivo. Como en Ramaditas y Guatacondo, en Caserones se añade madera a las construcciones, a modo de grandes pilares, para apoyar estructuralmente los muros y permitir la instalación de las techumbres.

En relación con los modos de organización espacial, Guatacondo reproduce una organización centralizada definida como una composición estable y concentrada, que se encuentra compuesta de diversos espacios secundarios agrupados en torno a uno central, dominante y de mayor tamaño (Ching 2008), articulada en simetría por un eje este-oeste que divide la aldea en la figura central, lo cual se refuerza con la instalación de los vanos de esta estructura en dicho eje. Ramaditas, además de las estructuras dispersas, presenta tres conglomerados en que se reproduce la misma organización, pero de forma más irregular, acercándose también a la disposición agrupada. En la quebrada de Tarapacá, Pircas, evidentemente más disperso, presenta cinco conglomerados bien definidos, con la misma forma agrupada irregular. En este yacimiento, la superficie que comprometen estos grandes espacios es proporcionalmente muy similar a Ramaditas, acusando variaciones funcionales. Muy disímil es Caserones, probablemente el asentamiento más largo e intensamente ocupado, y por lo mismo, muy modificado, en el cual se observa un ordenamiento ecléctico, agrupado y simétri$\mathrm{co}$, con formas muy irregulares en el extremo oriental y fuertemente agrupados al centro y al oeste. Las plazas aparecen desplazadas del conjunto doméstico, sin la centralidad que se observa en Guatacondo, sino limitando el asentamiento al sur y al norte.

Paradigmáticamente, Warnier establece que:

"Towns and houses are neolithic innovations. This suggests that the passge from nomadic to sedentary life was accompanied by a drastic change in the closure of space articulated with equivalent changes in the techniques of the body. The trend, from the political and architectural point of view, seems to have been towards more closure, departing from the openness of the nomadic camp with its marked flexibility in spatial organization and social affiliation [...]" (2000: 193).

Lo interesante, en el caso de las aldeas formativas tarapaqueñas, es la forma en que este proceso tiene lugar y la variabilidad que adquieren los espacios públicos y domésticos. En efecto, vemos en el caso de Ramaditas y Guatacondo, que el patrón arquitectónico identificado presenta una relación similar en la superficie comprometida del espacio edificado de uso comunitario o público y los espacios domésticos, cercano al 40\% de superficie de uso común para ambos casos. En Ramaditas esto ocurre en una dinámica segmentada, mientras que en Guatacondo el conjunto total forma un solo cuerpo, concentrándose la superficie comunitaria en prácticamente una estructura, la plaza central de forma oval y $1.800 \mathrm{~m}^{2}$ construidos, constituyéndose en un sitio único entre el conjunto analizado. Lo anterior tiene relación con los usos/funciones de esta estructura y con la cantidad de personas y unidades domésticas que pueden ingresar y participar de dicho espacio, efectiva y teóricamente. Pircas en tal sentido, pese a su conformación más irregular, se acerca formalmente mucho más a Ramaditas.

En ambos casos, y también en una de las estructuras circulares amplias de Guatacondo, las evidencias arqueológicas señalan la realización de actividades domésticas de 
uso comunitario, como el almacenaje en pozos cavados, trabajo sobre herramientas, e inclusive evocan corrales para animales, como observáramos en algunos casos de arquitectura formativa en San Pedro de Atacama (Adán y Urbina 2007). Sabemos, que las prácticas de almacenaje y de tenencia de ganado forman parte fundamental del nuevo modo de vida del período Formativo, por lo cual seguramente, este uso "doméstico" debió estar recurrentemente ritualizado.

En Pircas y Ramaditas se define además una trama de circulación abierta, donde la estructura mayor tiene una función vestibular, en la cual la mayor parte de los recintos menores acceden y remiten desde este lugar central. Guatacondo, en cambio, con un monolito central y restos de ramadas contiguas a los muros, actualiza y monumentaliza dicho patrón. Su centralidad, con dos accesos orientados al poniente y el oriente, actúa como cuerpo central que organiza todo el asentamiento, a la vez que se distancia funcionalmente del resto del conjunto, como queda expresado en la singularidad de su tamaño y en la circulación que permite. Escasean las evidencias de funciones domésticas y se aspecta paradigmáticamente como espacio para la congregación social, permitiendo una intervisibilidad organizada y una disposición cardinal claramente orientada.

Sin lugar a duda, y tomado como conjunto, Caserones constituye un patrón diferente. En éste, la superficie que comprometen los espacios públicos es muy inferior a aquellos de uso doméstico. Los espacios públicos se desplazan desde el centro hacia los bordes, limitando y conteniendo al conjunto, junto con demostrar una vocación de mayor visibilidad desde el exterior. El cierre de esta aldea se refuerza en la construcción de su muro perimetral que además, señala una significativa inversión de trabajo organizado.

\section{* Espacios públicos, experiencia cotidiana Y ORDEN SOCIAL}

Qué ocurrió entonces en estos espacios comunitarios, públicos, de usos domésticos y rituales, de tal preponderancia en los conjuntos. Se trata evidentemente de una interrogante crucial en la comprensión de los desarrollos culturales de estas poblaciones. Los antecedentes arquitectónicos que hemos descrito junto a la información proporcionada por materiales muebles como la cerámica y los textiles (Figuras 12 y 13), nos permiten sugerir situaciones diferentes que bien podrían ser contemporáneas. Nuestra visión señala la necesidad de apreciar estos espacios de congregación en su diversidad, expresada arqueológicamente en sus relaciones contextuales, superficiales y subsuperficiales, para no imponer la categoría de plaza pública con toda su carga ilustrada y su universal fama en relación al surgimiento de la ciudadanía. En vez, vemos procesos dinámicos y complejos propios de los desarrollos locales y la raigambre cultural de los valles tarapaqueños.

En primer lugar, es evidente que estos espacios en diferentes niveles y maneras actuaron como ordenadores espaciales tanto del conjunto arquitectónico como para quienes habitaron y ocuparon el lugar (Foucault 2006). Su cualidad de inscripción permite además la implantación de narrativas espaciales de significación social más amplia, y por tanto, compartidas o disputadas (De Certeau 2007). Ello ocurre en un contexto económico y social en que el desarrollo de prácticas apropiadoras y productivas, como la recolección, la agricultura y el pastoreo, requerían estrategias de regulación y orden. Materialidades inmuebles como la cerámica, la textilería y la metalurgia dan cuenta de un proceso de complejización social, con acceso diferencial hacia ciertos bienes y recursos (Agüero 2012; Uribe y Vidal 2012). Diversos espacios públicos como las plazas y los patios, así como los cementerios, son espacios privilegiados para la exhibición y expresión de estas distinciones.

En Ramaditas y Pircas hay estructuras centrales a las cuales convergen la mayor parte de los vanos, las cuales, por tanto, permitieron y obligaron a una circulación diaria de los habitantes del conglomerado. Los restos allí depositados, como la relación entre la superficie comunitaria y doméstica, hacen suponer que congregaron actividades propias de la vida cotidiana, las cuales se alternarían con otras de orden festivo o religioso al nivel de la unidad o unidades domésticas que dichos patios pueden contener. Considerando el carácter vestibular de dichas estructuras, en estos espacios públicos se vive lo cotidiano, con relaciones cara a cara, continuas y obligadas. El orden social que allí se recrea, el cual pudo ser inclusive muy normado, seguramente la mayor parte del tiempo no superó el ámbito de la unidad doméstica, evitando la naturalización de formas de poder institucionalizada, la otra fuerza constituyente de este proceso (Clastres 1978; De Certeau 


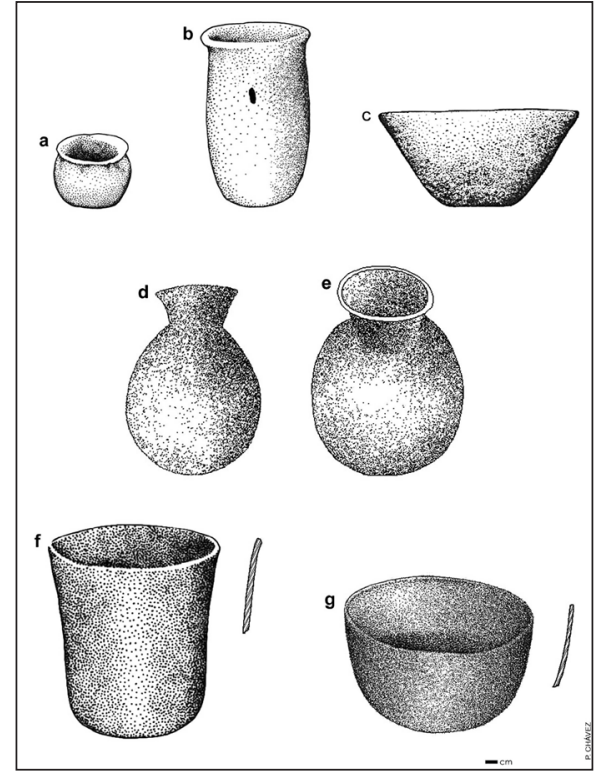

Figura 12. Cerámica del período Formativo en Tarapacá. Tomado de Uribe y Vidal (2012).

2007). En otros términos, dicho artefacto de uso público, por sus límites y su situación espacial en el asentamiento, no llega a constituirse en el teatro de la exhibición que suponen las grandes plazas (Turner 1987), sino que vuelve y se vincula resistentemente a lo cotidiano y doméstico, aquella práctica que les ha hecho fijarse en un territorio.

Guatacondo refleja una situación diferente, allí hay un espacio central bien delimitado, con escasos accesos. Su gran tamaño señala la posibilidad de congregar a un gran número de personas, cuyo ingreso ocurre bajo un significativo control espacial. Se observa además, un distanciamiento de lo doméstico, fijando la singularidad de este espacio comunitario y público, en que las ramadas junto a los muros interiores, adicionalmente, definen lugares para grupos o unidades domésticas. Esta plaza, como continente social privilegiado, en el que apenas encontramos depositación alfarera, debió permitir actos públicos que congregaban a la comunidad. La regulación espacial, no obstante, señala prácticas de control, de exclusión, o de una inclusión fuertemente normada, que se relaciona con la mantención del sentido de comunidad en el orden económico y social existente.

El acto de inclusión a estas plazas Formativas, no obstante, no puede ser entendido ni idealizado en términos

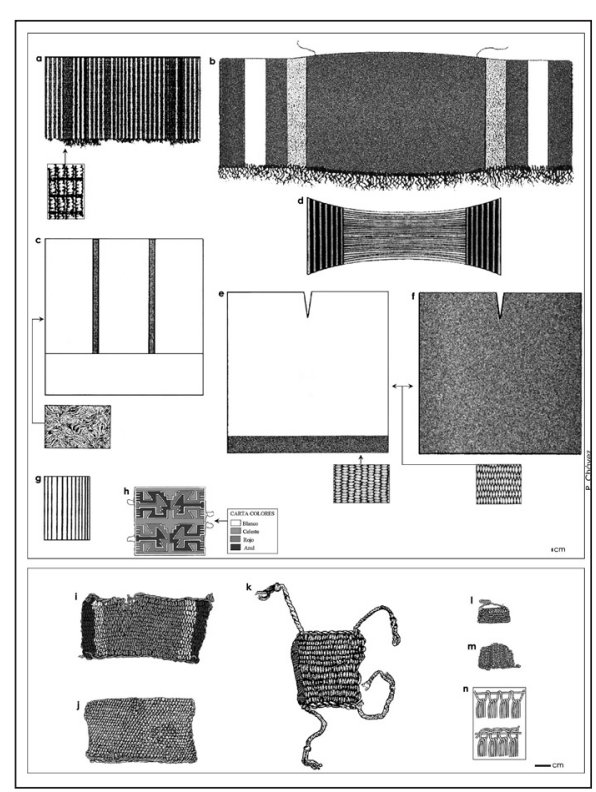

Figura 13. Textiles del período Formativo Tardío en Tarapacá (400-900 DC).

de un acto "democrático" a la que nos podría incitar una construcción histórica modernizante (Bajtin 2003: 23, 120). Es sobre todo una forma de congregación, en la que como este autor señala, lo que importa es la recreación del cuerpo social y la forma en que cada individualidad participa de este cuerpo colectivo. La creación de estos espacios edificados da cuenta justamente de la necesidad de relevar y contener este cuerpo colectivo`. A juzgar por la evidencia con que contamos, suponemos que dichos espacios públicos pequeños, acotados y reiterados, congregarían una acción, familiar, liberadora y resistente, mientras que las grandes plazas centrales comienzan a transitar lentamente a una forma arquitectónica dirigida con mayor énfasis al ordenamiento social y formas más institucionalizadas de administración, disputa y reproducción de los poderes. Consideremos la posible contemporaneidad de ambas clases de espacios.

Caserones, al final de la secuencia, acota visiblemente los espacios públicos y los segrega espacialmente, evidencian-

9 En su estudio sobre la cultura popular europea de la Edad Media, Bajtin observa que las plazas públicas se constituyen en un territorio popular por excelencia, en el que reina un trato libre y familiar, a diferencia de la etiqueta y urbanidad que se requerían en los templos y palacios (2003: 139). 
do claros principios de exclusión social que, sin embargo, ocurren sin la centralidad de los momentos iniciales.

El mito del progreso, que ha privilegiado los enfoques neoevolucionistas aplicados a la comprensión del Formativo o el Neolítico, simpatiza con el inevitable destino o tragedia de los comunes, de sus espacios públicos y sus recursos naturales (Hardin 1968). No obstante, el registro arquitectónico que hemos descrito da cuenta de estrategias sociales y materiales que permiten y acuerdan la mantención de un orden social que resulta funcional, sin obviar los procesos de distinción y diferenciación social inherentes a toda sociedad, a la preservación de la comunidad y su modo de vida. Tecnologías de poder y estrategias de resistencia actúan conjuntamente en la estructuración y ocupación de esta nueva arquitectura durante gran parte del Formativo, sin evidenciar transformaciones dramáticas en la transición hacia el período Intermedio Tardío (ca. 900 DC), sino más bien ciertas continuidades en las prácticas constructivas. No obstante, la oclusión que se evidencia en Caserones, con plazas y muros, parece ser la indicación material de la imposición de un nuevo orden social en que lo doméstico se distancia de lo público, quedando contenido o clausurado entre sus plazas.

\section{* Consideraciones finales}

Hemos abordado, desde la perspectiva de la reflexión arqueológica y arquitectónica, tempranas evidencias de arquitectura comunitaria, las cualidades de sus espacios públicos, las materialidades muebles e inmuebles asociadas a éstas, así como las prácticas sociales que allí se desarrollaron para el caso del período Formativo en Tarapacá. Proponemos que la tarea de pensar la arquitectura se nutre significativamente en el análisis de manifestaciones arqueológicas, ampliando históricamente nuestra comprensión de la dinámica y naturaleza de los espacios edificados, como asimismo promoviendo un diálogo que permita acercar enfoques teóricos y metodológicos de diferentes disciplinas. Mirar la arquitectura doméstica y pública como expresión de tecnologías de poder y espacio para las estrategias de resistencia constituye un desafío fundamental para la reflexión disciplinaria, ampliando las posibilidades analíticas de la arquitectura, y con ello, el conocimiento sobre sus antiguos moradores.

Agradecimientos A FONDECYT, por financiar nuestro proyecto 1080458 "Período Formativo en Tarapacá. Progreso y tragedia social en la evolución y la temprana complejidad cultural del Norte Grande de Chile, Andes, Centro-Sur", y a Mauricio Uribe, su investigador responsable.
ADÁN, L. y S. URBINA, 2007. Arquitectura formativa de San Pedro de Atacama. Estudios Atacameños, Arqueología y Antropología Surandinas 34: 7-30.

ADÁN, L., M. URIBE y S. URBINA, 2007. Arquitectura pública y doméstica en las quebradas de Tarapacá: Asentamiento y dinámica social en el Norte Grande de Chile. En La vivienda, la comunidady el territorio, A. Nielsen, C. Rivolta, P. Mercolli, M. Vásquez y V. Seldes (Eds.), pp. 183-206. Editorial Brujas, Córdoba.

AGÜERO, C., 2012. Textiles del asentamiento Caserones y su cementerio: Significado social y político para la población tarapaqueña durante el período Formativo (norte de Chile). Revista Chilena de Antropología 26 (2): 59-94.

AGÜERO, C., M. URIBE, P. AYALA, B. CASES y C. CARRASCO, 2001. Ceremonialismo del período Formativo en Quillagua, Norte Grande de Chile. Boletín de la Sociedad Chilena de Arqueología 32: 24-34.

ALDENDERFER, M. y C. STANISH, 1993. Domestic architecture, household archaeology, and the past in South Central Andes. En Domestic architecture, ethnicity, and complementarity in the South Central Andes, M. Aldenderfer (Ed.), pp. 1-12. University of Iowa Press, Iowa.

ANDERSON, B., 1993. Comunidades imaginadas. Reflexiones sobre el origen y la difusión del nacionalismo. Fondo de Cultura Económica, México D.F.

AYALA, P., 2001. Las sociedades formativas del Altiplano Meridional y su relación con el Norte Grande de Chile. Estudios Atacameños 21: 7-39.

BAJTIN, M., 2003. La cultura popular en la Edad Media y en el Renacimiento. El contexto de François Rabelais. Alianza Editorial, Madrid.

BERENGUER, J., 2008. La costa, un lugar para vivir. En Pescadores de la niebla. Los changos y sus ancestros, J. Berenguer (Ed.), pp. 2250. Museo Chileno de Arte Precolombino, Santiago. 
BLIER, S. P., 2006. Vernacular architecture. Handbook of material culture, C. Tilley, W. Keane, S. Kuchler, M. Rowlands y P. Spyer (Eds.), pp. 230-253. Sage Publications, Londres.

CASTRO, V., F. MALDONADO y M. VÁSQUEZ, 1993. Arquitectura del pukara de Turi. Actas del XII Congreso Nacional de Arqueología Chilena, pp.79-106. Temuco.

CLASTRES, P., 1978. La sociedad contra el Estado. Monte Ávila Editores, Barcelona.

CONTRERAS, R., J. CRUZ, A. LLAGOSTERA, H. GARCÉS, P. NÚÑEZ, O. RODRÍGUEZ, H. GÁRATE y G. BECERRA, 2007. Los Bronces 1: Un asentamiento de 5500 años en la costa de Taltal. Museo Augusto Capdeville, Taltal.

CERVELLINO, M. y F. TÉLLEZ, 1980. Emergencia y desarrollo de una aldea prehispánica de Quillagua, Antofagasta. Contribución Arqueológica 1: 1-235.

CHARTIER, R., 2003. Espacio público, crítica y desacralización en el siglo XVIII. Los orígenes culturales de la revolución francesa. Editorial Gedisa, Barcelona.

CHING, F., 2008. Arquitectura, forma, espacio y orden. Editorial Gustavo Gili, Barcelona.

DAUELSBERG, P., 1985. Faldas del Morro: Fase cultural agroalfarera temprana. Chungara 14: 7-44.

DE CERTAU, M., 2007. La invención de lo cotidiano. I. Las artes de hacer. Universidad Iberoaméricana, México D.F.

FOCACCI, G., 1974. Excavaciones en el cementerio de Playa Miller 7. Arica, Chile. Chungara 3: 23-74.

FOUCAULT, M., 2006. Vigilar y castigar. Nacimiento de la prisión. Siglo XXI Editores, Madrid.

FRAZER, J. G., 1995 [1890]. La rama dorada. Fondo de Cultura Económica, Bogotá.

GRAFFAM, G., M. RIVERAy A. CAREVIC, 1996. Ancient metallurgy in the Atacama: Evidence for copper smelting during Chile's Early Ceramic period. Latin American Antiquity 7 (2): 101-113.

HARDIN, G., 1968. The tragedy of the commons. Science 162: 12431248.

HODDER, I., 1994. Architecture and meaning: The example of neolithic houses and tombs. En Architecture and order. Approaches to social space, M. Parker Pearson y C. Richards (Eds.), pp. 73-86. Routledge, Londres y Nueva York.

INGOLD, T., 2004. Culture on the ground. The world perceived through the feet. Journal of Material Culture 9 (3):315-340.

LÉVI-STRAUSS, C., 1986. Mitológicas. I. Lo crudo y lo cocido. Fondo de Cultura Económica, México D.F.
LUMBRERAS, L., 2006. Un Formativo sin cerámica y cerámica preformativa. Estudios Atacameños, Arqueología y Antropología Surandinas 32: 11-34.

LYNCH, K., 2000. La imagen de la ciudad. Editorial Gustavo Gili, Barcelona.

MARTINDALE, A., 2005. A method for analyzing vernacular architecture: A case study from the Ramaditas site, Chile. En Arqueología del Desierto de Atacama: La etapa formativa en el área de Ramaditas/Guatacondo, M. Rivera (Ed.), pp. 133-173. Editorial Universidad Bolivariana, Santiago.

MAUSS, M., 2006. Manual de etnografía. Fondo de Cultura Económica, México D.F.

MEIGHAN, C., 1980. Archaeology of Guatacondo, Chile. Prehistoric trails of Atacama: Archaeology of Northern Chile. En Monumenta Archaeologica 7, C. Meighan y D. True (Eds.), pp. 99-126. The Institute of Archaeology, University of California, Los Angeles.

MOSTNY, G., 1970. La subárea arqueológica de Guatacondo. Boletín del Museo Nacional de Historia Natural XXIX (16): 271-287.

MUÑOZ, I., 1980. Túmulos funerarios: evidencias del proceso de agriculturización en los valles bajos de Arica. Memoria de Título en Arqueología, Universidad del Norte, Antofagasta.

1987. Enterramientos en túmulos en el valle de Azapa: Nuevas evidencias para definir la fase Alto Ramírez en el extremo Norte de Chile. Chungara 19: 93-127.

1989. El período Formativo en el Norte Grande (1000 AC a 500 DC). En Culturas de Chile. Prehistoria, desde sus orígenes a los albores de la Conquista, J. Hidalgo, V. Schiappacasse, H. Niemeyer, C. Aldunate e I. Solimano (Eds.), pp. 107-128. Editorial Andrés Bello, Santiago.

2004. El período Formativo en los valles del norte de Chile y sur del Perú: Nuevas evidencias y comentarios. Actas del $X V$ Congreso Nacional de Arqueología Chilena, vol. 1, pp. 213-225. Arica.

NIELSEN, A., 2006. Plazas para los antepasados: Descentralización y poder corporativo en las formaciones políticas preincaicas de los Andes circumpuneños. Estudios Atacameños 31: 63-89.

NORBERG-SCHULZ, C., 1975. Nuevos caminos de la arquitectura. Existencia, espacio y arquitectura. Editorial Blume, Barcelona.

NÚÑEZ, L., 1966. Caserones I, una aldea prehispánica del norte de Chile. Estudios arqueológicos 2: 25-29.

1982. Temprana emergencia de sedentarismo en el desierto chileno: Proyecto Caserones. Chungara: 9: 80-122.

1984. El asentamiento Pircas: Nuevas evidencias de tempranas ocupaciones agrarias en el norte de Chile. Estudios Atacameños 7: 117-139. 
1989. Hacia la producción de alimentos y la vida sedentaria (5000 AC-500 DC). En Culturas de Chile. Prehistoria, desde sus orígenes a los albores de la Conquista, J. Hidalgo, V. Schiappacasse, $\mathrm{H}$. Niemeyer, C. Aldunate e I. Solimano (Eds.), pp. 81-105. Editorial Andrés Bello, Santiago.

2005. La naturaleza de la expansión aldeana durante el Formativo Tardío en la cuenca de Atacama. Chungara, Revista de Antropología Chilena 37 (2): 165-193.

NÚÑEZ, L. y T. DILLEHAY, 1995. Movilidad giratoria, armonía social y desarrollo en los Andes Meridionales: patrones de tráfico e interacción económica. Universidad del Norte, Antofagasta.

NÚÑEZ, L., V. ZLATAR y P. NÚÑEZ, 1975. Relaciones prehistóricas trasandinas entre el noroeste argentino y norte chileno (período cerámico). Documentos de Trabajo 6: 1-24.

NÚÑEZ, P., 1983. Aldeas tarapaqueñas, notas y comentarios. Chungara 10: 29-37.

PARKER PEARSON, M, y C. RICHARDS, 1994a. Ordering the world: Perceptions of architecture, space and time. En Architecture and order. Approaches to social space, M. Parker Pearson y C. Richards (Eds.), pp. 1-37. Routledge, Londres y Nueva York.

1994b. Architecture and order: Spatial representation and archaeology. En Architecture and order. Approaches to social space, M. Parker Pearson y C. Richards (Eds.), pp. 38-72. Routledge, Londres y Nueva York.

PELLEGRINO, C., 2011. Propuesta de intervención de sitios arqueológicos en la quebrada de Tarapacá: El caso de la aldea de Caserones. Werkén 14 (1): 87-104.

RIVERA, M., 1975. Una hipótesis sobre movimientos poblacionales transaltiplánicos a las costas del norte de Chile. Chungara $5: 7-31$.

1985. Alto Ramírez y Tiwanaku: Un caso de interpretación simbólica. Diálogo Andino 4:39-58.

1994. Hacia la complejidad social y política: El desarrollo Alto Ramírez del norte de Chile. Diálogo Andino 13: 9-38.

2005. Arqueología del Desierto de Atacama. La etapa formativa en el área de Ramaditas/Guatacondo. Editorial Universidad Bolivariana, Santiago.

RIVERA, M., A. SHEA, A. CAREVIC y G. GRAFFAM, 1995-96. En torno a los orígenes de las sociedades complejas andinas: Excavaciones en Ramaditas, una aldea formativa del desierto de Atacama, Chile. Diálogo Andino 14/15: 205-239.

ROMERO, A., C. SANTORO, D. VALENZUELA, J. CHACAMA, E. ROSELLÓ y L. PIACENZA, 2004. Túmulos, ideología y paisaje de la fase alto Ramírez del valle de Azapa. Actas del XV Congreso de Arqueología Chilena, vol. 1, pp. 261-272. Arica.
SANTORO, C., 1980. Fase Azapa: Transición del Arcaico al desarrollo agrario inicial en los valles bajos de Arica. Chungara 7: 46-56.

1981. Formativo Temprano en el extremo norte de Chile. Chungara 8:33-62.

RAFFINO, R., 1990. Poblaciones indígenas de la Argentina. Editorial TEA, Buenos Aires.

ROSALDO, R., 1999. Ciudadanía cultural, desigualdad y multiculturalidad. El Bordo 03. http://www.tij.uia.mx/academicos/ elbordo/voloz/contenido.html

TURNER, V., 1987. The anthropology of performance. PAJ Publications, Nueva York.

URBINA, S., L. ADÁN, C. MORAGAS, S. OLMOS y R. AJATA, 2011. Arquitectura de asentamientos de la costa de Tarapacá, norte de Chile. Estudios Atacameños, Arqueología y Antropología Surandinas 41: 21-348.

URBINA, S., L. ADÁN y C. PELLEGRINO, 2012. Arquitecturas formativas de las quebradas de Guatacondo y Tarapacá a través del proceso aldeano (ca.900 AC-1000 DC). Boletín del Museo Chileno de Arte Precolombino 17 (1):31-60.

URIBE, M., 2009. El período Formativo de Tarapacá y su cerámica: Avances sobre complejidad social en la costa del Norte Grande de Chile (900 AC-80o DC). Estudios Atacameños, Arqueología y Antropología Surandinas 37: 5-27.

URIBE, M., y L. ADÁN, 2012. Acerca de evolución, Neolítico, Formativo y complejidad: Pensando el cambio desde Tarapacá (900 AC-80o DC). Actas del XVIII Congreso Nacional de Arqueología Chilena (Valparaíso), pp. 21-32. Sociedad Chilena de Arqueología, Santiago.

URIBE, M. y E. VIDAL, 2012. Sobre la secuencia cerámica del período Formativo de Tarapacá (900 AC-900 DC): Estudios en Pircas, Caserones, Guatacondo y Ramaditas, norte de Chile. Chungara, Revista de Antropología Chilena 44 (2): 209-245.

URRY, J., 1991. Time and space in Giddens' social theory. En Giddens' theory of structuration. A critical appreciation, C. Bryant e I. Jary (Eds.), pp. 160-175. Routledge, Londres.

WARNIER, J. P., 2006. Inside and outside: Surfaces and containers. En Handbook of Material Culture, C. Tilley, W. Keane, S. Küchler, M. Rowlands y P. Spyer (Eds.), pp. 186-195. Sage Pubications, Londres.

WHITELAW, T., 1994. Order without architecture. Functional, social and symbolic dimensiones in hunther-gatherer settlement organization. En Architecture and order. Approaches to social space, M. Parker Pearson y C. Richards (Ed.), pp. 217-243. Routledge, Londres y Nueva York.

ZLATAR, V., 1983. Replanteamiento sobre el problema Caleta Huelén 42. Chungara 10: 21-28. 